OPEN ACCESS

Edited by:

Constantinos Petrovas, Centre Hospitalier Universitaire Vaudois (CHUV), Switzerland

Reviewed by: Morgane Bomsel, Centre National de la Recherche Scientifique (CNRS), France Bruce David Wines, Burnet Institute, Australia

${ }^{*}$ Correspondence: Marzena Pazgier marzena.pazgier@usuhs.edu

Specialty section: This article was submitted to Viral Immunology, a section of the journal Frontiers in Immunology

Received: 01 October 2021 Accepted: 09 December 2021 Published: 06 January 2022

Citation:

Tolbert WD, Nguyen DN, Tuyishime M, Crowley $A R$, Chen $Y$, Jha $S$, Goodman D, Bekker V, Mudrak SV, DeVico AL, Lewis GK, Theis JF, Pinter A, Moody MA, Easterhoff $D$, Wiehe K, Pollara J, Saunders KO, Tomaras GD, Ackerman M, Ferrari G and Pazgier M (2022) Structure and FC-Effector Function of Rhesusized Variants of Human Anti-HIV-1 lgG1s.

Front. Immunol. 12:787603. doi: 10.3389/fimmu.2021.787603

\section{Structure and Fc-Effector Function of Rhesusized Variants of Human Anti-HIV-1 IgG1s}

\author{
William D. Tolbert ${ }^{1}$, Dung N. Nguyen ${ }^{1}$, Marina Tuyishime ${ }^{2,3,4}$, Andrew R. Crowley, \\ Yaozong Chen ${ }^{1}$, Shalini Jha ${ }^{2,3}$, Derrick Goodman ${ }^{2,3,4}$, Valerie Bekker ${ }^{2,3,4}$, \\ Sarah V. Mudrak ${ }^{2,3,4}$, Anthony L. DeVico ${ }^{6}$, George K. Lewis ${ }^{6}$, James F. Theis ${ }^{7}$, \\ Abraham Pinter ${ }^{7}$, M. Anthony Moody ${ }^{3,8}$, David Easterhoff ${ }^{3}$, Kevin Wiehe $^{3,9}$, \\ Justin Pollara 2,3,4, Kevin O. Saunders ${ }^{2,3}$, Georgia D. Tomaras ${ }^{2,3,4}$, Margaret Ackerman ${ }^{5}$, \\ Guido Ferrari $^{2,3,4}$ and Marzena Pazgier ${ }^{1 *}$

\begin{abstract}
Infectious Disease Division, Department of Medicine of Uniformed Services University of the Health Sciences, Bethesda, MD, United States, ${ }^{2}$ Department of Surgery, Duke University School of Medicine, Durham, NC, United States,

${ }^{3}$ Human Vaccine Institute, Duke University School of Medicine, Durham, NC, United States, ${ }^{4}$ Center for Human Systems Immunology, Duke University School of Medicine, Durham, NC, United States, ${ }^{5}$ Thayer School of Engineering, Dartmouth College, Hanover, NH, United States, ${ }^{6}$ Division of Vaccine Research, Institute of Human Virology, University of Maryland School of Medicine, Baltimore, MD, United States, ${ }^{7}$ Public Health Research Institute, New Jersey Medical School, Rutgers University, Newark, NJ, United States, ${ }^{8}$ Department of Pediatrics, Duke University School of Medicine, Durham, NC, United States, ${ }^{9}$ Department of Medicine, Duke University School of Medicine, Durham, NC, United States
\end{abstract}

Passive transfer of monoclonal antibodies (mAbs) of human origin into Non-Human Primates (NHPs), especially those which function predominantly by a Fc-effector mechanism, requires an a priori preparation step, in which the human mAb is reengineered to an equivalent NHP IgG subclass. This can be achieved by changing both the Fc and Fab sequence while simultaneously maintaining the epitope specificity of the parent antibody. This Ab reengineering process, referred to as rhesusization, can be challenging because the simple grafting of the complementarity determining regions (CDRs) into an NHP IgG subclass may impact the functionality of the mAb. Here we describe the successful rhesusization of a set of human mAbs targeting HIV-1 envelope (Env) epitopes involved in potent Fc-effector function against the virus. This set includes a mAb targeting a linear gp120 V1V2 epitope isolated from a RV144 vaccinee, a gp120 conformational epitope within the Cluster A region isolated from a RV305 vaccinated individual, and a linear gp41 epitope within the immunodominant Cys-loop region commonly targeted by most HIV-1 infected individuals. Structural analyses confirm that the rhesusized variants bind their respective Env antigens with almost identical specificity preserving epitope footprints and most antigen-Fab atomic contacts with constant regions folded as in control RM IgG1s. In addition, functional analyses confirm preservation of the Fc effector function of the rhesusized mAbs including the ability to mediate Antibody Dependent Cell-mediated Cytotoxicity (ADCC) and antibody dependent cellular phagocytosis 
by monocytes (ADCP) and neutrophils (ADNP) with potencies comparable to native macaque antibodies of similar specificity. While the antibodies chosen here are relevant for the examination of the correlates of protection in HIV-1 vaccine trials, the methods used are generally applicable to antibodies for other purposes.

Keywords: antibody engineering, rhesusization, Fc-effector function, non-human primates, HIV

\section{INTRODUCTION}

The only vaccine to show efficacy although limited against HIV-1 infection has been the RV144 vaccine trial in Thailand consisting of a canarypox ALVAC-HIV DNA prime and AIDSVAX B/E protein boost which showed an overall efficacy of $31.2 \%$ against HIV-1 acquisition (1). Secondary analyses of correlates of reduced risk of infection revealed the role played by antibodydependent cellular-cytotoxicity (ADCC) and Fc effector functions against HIV-1 Env in the absence of high levels of Env-specific serum IgA (2-5). Breakthrough infections showed vaccine pressure on the V2 loop region of Env which could be seen by sequence changes in V2 (6-9). Many attempts to reproduce this protective effect with the same or similar vaccine regimens have succeeded in non-human primates (NHP) (10-18), but a study in humans did not show efficacy, potentially due to differences in adjuvant (MF59 vs. alum), and subtype and sequences of the immunogens (subtype $C$ vs $A E$ ) $(19,20)$. While still under investigation, additional reasons for this discordance may include differences in the circulating strains in human populations versus those in NHP challenge stocks and most importantly, human-NHP interspecies differences in host genetics that may contribute to the type, magnitude, functionality and duration of the induced immune response. However, the HVTN 505 HIV-1 clinical efficacy trial consisting of a DNA and Adenovirus 5 vaccine regimen, despite lacking overall efficacy, did show a correlation between anti-Env serum IgG3, antibody dependent cellular phagocytosis (ADCP) and in vitro Fc $\gamma$ RIIa engagement and a reduced risk of HIV-1 infection as well as a correlation between FcyRIIa engagement and a decreased viral load setpoint in breakthrough vaccinees (21), indicating that strategies to induce more potent antibody $\mathrm{Fc}$ effector functions in a greater proportion of vaccinees are needed.

Rhesus macaque (RM), Macaca mulatta, the most often used primate in NHP studies, shares approximately 93\% genome identity with humans, but that high degree of similarity breaks down in immune system genes. There are significant differences in immunoglobulin (IgG) subclasses, Fc receptor diversity and $\mathrm{Fc} \gamma$ receptor $(\mathrm{Fc} \gamma \mathrm{R})$ expression patterns between human and $\mathrm{RM}$ that complicate the translation of experimental results in RM to humans (22-24). RM IgG subclasses are in general more similar to each other than are their human counterparts; both macaques and humans have four IgG subclasses, but macaques lack highly divergent subclasses such as human IgG3 with its long repetitive hinge region. Macaques also lack an FcyRIIIb gene which was the result of a gene duplication event that occurred after the divergence of macaques from other higher primates (25);

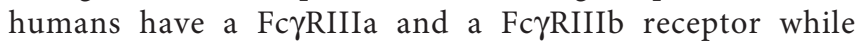

macaques only have a FcyRIIIa receptor. Both have FcyRIIa (activating) and Fc $\gamma$ RIIb (inhibitory) receptors. Although human IgGs can bind macaque FcyRs, these and other differences change the $\mathrm{Fc} / \mathrm{Fc} \gamma \mathrm{R}$ functional landscape between the two species.

Given the difficulty in reproducing RV144 vaccine limited efficacy results in other vaccine trials, it is important to be able to define mechanistic aspects of the correlates of protection conferred by the human vaccine in NHP. This is typically done for antibodies cloned from HIV-1 infected or vaccinated individuals by passive transfer of the monoclonal antibody $(\mathrm{mAb})$ or $\mathrm{mAb}$ mix into NHP followed by a viral challenge to test its ability to protect against infection or to provide postinfection control. Many NHP passive transfer trials have been used to successfully test antibodies that function predominately by neutralization, where an Fc effector mismatch is less of an issue (26-28). In these studies, a mAb of human origin is directly transferred into NHP without reengineering to the equivalent RM IgG subclass. Although convenient, such approaches potentially suffer from anti-drug antibody (ADA) responses that can quickly remove species mismatched antibodies from circulation, thereby abrogating any functional effect. The longer the duration of the trial, the higher the probability of inducing such responses becomes (29). Furthermore, passive transfer testing of $\mathrm{mAbs}$ that function predominately by Fc-effector mechanisms, such as those from the RV144 trial, require both a minimization of the ADA response and a match of the Fc of the infused antibody to that of the host to more accurately mirror what is happening in macaque immunization trials. For human mAbs to be tested in RM this means rhesusization of both the Fc and Fab while simultaneously maintaining epitope specificity.

Here we describe a successful attempt to rhesusize a set of human mAbs targeting HIV-1 Env epitopes involved in potent Fc-effector mechanisms. This set includes a mAb targeting the linear gp120 V1V2 epitope isolated from a RV144 vaccinee (30), a gp120 conformational epitope within the Cluster A region isolated from a RV305 vaccinated individual, a RV144 vaccinee who had further boosts with RV144 immunogens in the RV305 vaccine trial that was designed to test if correlates of protection in RV144 could be boosted in RV144 vaccinees (31), and a linear gp41 epitope within the immunodominant Cys-loop region commonly targeted by most HIV-1 infected individuals (32). Antibodies binding to these three regions have been implicated in protection from infection from HIV-1, but not in neutralization of the virus. Structural analyses confirm that the rhesusized variants bind their respective Env antigens with almost identical specificity as their human counterpartspreserving epitope footprints and most antigen-Fab atomic 
contacts with constant regions folded as in control RM IgG1. Functional analyses confirm their Fc effector functionality, including the ability to mediate Antibody Dependent Cellmediated Cytotoxicity (ADCC), Antibody Dependent Cellular Phagocytosis by monocytes (ADCP), and Antibody Dependent Cellular Phagocytosis by neutrophils (ADNP) with potencies comparable to native macaque antibodies of similar specificity. This will facilitate the testing of their impact on the virus in the future in an animal model. While the antibodies chosen here are relevant for examining the correlates of protection in HIV-1 trials the methods used are generally applicable to antibodies for other purposes.

\section{MATERIAL AND METHODS}

\section{Rhesusization of Antibodies}

Human variable regions were rhesusized as previously described with minor modifications (33). For each human antibody sequence of interest, we used the immunogenetics sequence analysis software Cloanalyst (https://www.bu.edu/computationalimmunology/ research/software) to infer an unmutated common ancestor (UCA) sequence using only rhesus germline immunoglobulin gene segments. In this approach, Cloanalyst aligns the human antibody sequence to the closest rhesus $\mathrm{V}, \mathrm{D}$, and $\mathrm{J}$ gene segments using Cloanalyst's rhesus Ig gene segment library which is based on a draft version of genome sequencing of the rhesus Ig loci (34). The resulting rhesus UCA is thus comprised of the rhesus $\mathrm{V}, \mathrm{D}$, and J gene segments with the highest identity to the human antibody sequence. Amino acids with high uncertainty in the inference of the rhesus UCA were changed to match the human amino acid at that position. The rhesus UCA amino acid sequence and the human amino acid sequence were then aligned, and CDR1, 2 , and 3 of the rhesus UCA were replaced with the corresponding CDR1, 2, and 3 of the human amino acid sequence producing the rhesusized antibody sequence. The rhesusized v-regions for the heavy and light chain were attached to macaque constant regions (AF045537, AF050635, FJ795843).

\section{Antibody Expression and Purification}

IgGs were prepared by co-transfection of heavy and light chain plasmids into HEK expi293F cells (Thermo Fisher Scientific) grown in expi293F expression medium in $8 \% \mathrm{CO}_{2}$. Seven days post-transfection cells were pelleted by centrifugation and the medium filtered. IgGs were purified by passage of the medium over a HiTrap protein A column (GE Healthcare) equilibrated in PBS. IgGs were eluted with $0.1 \mathrm{M}$ glycine $\mathrm{pH} 3.0$ and the $\mathrm{pH}$ of the eluted protein immediately raised to neutral $\mathrm{pH}$ by addition of $1 \mathrm{M}$ Tris- $\mathrm{HCl} \mathrm{pH}$ 8.5. Fabs were generated by papain digest. IgGs were first incubated with immobilized papain (Thermo Fisher Scientific) at $37^{\circ} \mathrm{C}$ for $3-4$ hours in $20 \mathrm{mM}$ sodium phosphate $\mathrm{pH} 7.2$ supplemented with $3.5 \mathrm{mg} / \mathrm{ml}$ cysteine. Immobilized papain agarose was removed by centrifugation and the supernatant filtered. Fabs were separated from undigested IgG and $\mathrm{Fc}$ by passage over a HiTrap protein A column. Fabs were then further purified by size exclusion chromatography over a Superdex 200 gel filtration column (GE Healthcare) equilibrated in $20 \mathrm{mM}$ Tris- $\mathrm{HCl} \mathrm{pH} 7.2$ and $100 \mathrm{mM}$ ammonium acetate.

\section{Preparation of Protein Complexes}

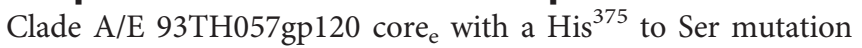
was prepared by transfection of $\mathrm{GnT}^{-}{ }^{-} \mathrm{HEK} 293 \mathrm{~F}$ Freestyle cells (Thermo Fisher Scientific) with $0.5 \mathrm{mg}$ of plasmid/liter of culture. Cells were grown in Freestyle 293 medium (Thermo Fisher Scientific) supplemented with 2.5\% Ultra Low IgG Fetal Bovine Serum (FBS) (Gibco) in $8 \% \mathrm{CO}_{2}$ for 7 days. Cells were pelleted, the medium filtered, and gp120 was purified from medium by passage over a $17 \mathrm{~b}$ affinity column which consisted of the anti-gp120 antibody $17 \mathrm{~b}$ covalently linked to protein A agarose. gp120 was eluted from the column with $0.1 \mathrm{M}$ glycine $\mathrm{pH} 3.0$ and the $\mathrm{pH}$ raised after elution by addition of $1 \mathrm{M}$ Tris$\mathrm{HCl} \mathrm{pH} \mathrm{8.5.} \mathrm{The} \mathrm{protein} \mathrm{was} \mathrm{concentrated} \mathrm{and} \mathrm{the} \mathrm{buffer}$ exchanged for $50 \mathrm{mM}$ sodium acetate $\mathrm{pH} 6.0$ and $300 \mathrm{mM}$ sodium chloride. Glycans were then truncated by addition of Endo $\mathrm{H}_{\mathrm{f}}$ (New England Biolabs) and incubation at $37^{\circ} \mathrm{C}$ overnight. Endo $\mathrm{H}_{\mathrm{f}}$, endoglycosidase $\mathrm{H}$ linked to maltose binding protein, was removed by passage over an amylose column (New England Biolabs) equilibrated in $25 \mathrm{mM}$ Tris$\mathrm{HCl} \mathrm{pH} 7.2$ and $200 \mathrm{mM}$ sodium chloride. The flow through fractions containing gp120 were further purified by size exclusion chromatography over a Superdex 200 gel filtration column (GE Healthcare) equilibrated in $20 \mathrm{mM}$ Tris- $\mathrm{HCl}$ pH 7.2 and $100 \mathrm{mM}$ ammonium acetate prior to use in complex formation with RhDH677.3 Fab. A V2 peptide corresponding to the clade A/E 92TH023 gp120 V2 loop sequence (Asp ${ }^{167}$-LysLys-Gln-Lys-Val-His-Ala-Leu-Phe-Tyr-Lys-Leu-Asp-Ile-ValPro-Ile ${ }^{184}$ ) was synthesized by Genescript (www.genescript.com) without modifications for use in complex formation with RhDH827 Fab.

The C1C2 Cluster A region RhDH677.3 complex was made by mixing RhDH677.3 Fab with purified clade A/E 93TH057gp120 core $_{\mathrm{e}}$ and the CD4 mimetic M48U1 in a molar ration of 1.2:1.2:1 of Fab:M48U1:gp120. The complex was allowed to incubate on ice for 30 minutes before purification by size exclusion chromatography over a Superdex 200 gel filtration column equilibrated in $20 \mathrm{mM}$ Tris- $\mathrm{HCl} \mathrm{pH} 7.2$ and $100 \mathrm{mM}$ ammonium acetate. The V1V2 region RhDH827 complex was made by mixing RhDH827 Fab with V2 peptide resuspended in water in a molar ratio of $1.2: 1$ peptide:Fab. The complex was incubated on ice for 30 minutes and purified by size exclusion chromatography over a Superdex 200 column equilibrated in $20 \mathrm{mM}$ Tris- $\mathrm{HCl} \mathrm{pH} 7.2$ and $100 \mathrm{mM}$ ammonium acetate. In both cases elution fractions corresponding to the complex molecular weight were combined and concentrated to approximately $10 \mathrm{mg} / \mathrm{ml}$ for use in crystallization trials.

\section{Surface Plasmon Resonance Affinity Measurements of IgGs to Antigens}

All surface plasma resonance (SPR) assays of IgGs to antigens were performed on a Biacore 3000 (GE Healthcare) with a 
running buffer of $10 \mathrm{mM}$ HEPES pH 7.5 and $150 \mathrm{mM} \mathrm{NaCl}$ supplemented with $0.05 \%$ Tween 20 at $25^{\circ}$ C. Kinetic measurements were done by immobilizing IgG on a protein $\mathrm{A}$ chip (Cytiva) and passage of serial dilutions of antigen in running buffer over the chip for 200 seconds. Complexes were then allowed to dissociate for 400 seconds by passage of running buffer at the same flow rate. IgG was removed from chip using regeneration buffer, $100 \mathrm{mM}$ glycine $\mathrm{pH} 2.5$, and fresh $\mathrm{IgG}$ reapplied between cycles. The antigen for $\mathrm{C} 1 \mathrm{C} 2$ Cluster $\mathrm{A}$ region RM JR4, DH677.3, and RhDH677.3 was monomeric full length single chain (FLSC), a covalent dimer of gp120 $\mathrm{BaL}$ and CD4 that specifically exposes CD4i epitopes (35), in a concentration range of 6.25 to $200 \mathrm{nM}$ and IgGs were immobilized on the protein A chip to a response unit (RU) of $\sim 60-120$. The antigen for gp41 region $7 \mathrm{~B} 2$ and $\mathrm{Rh} 7 \mathrm{~B} 2$ was a synthetic gp41 peptide (residues 596-606) with C-terminal amidation (GenScript) in a concentration range of $6.4-25.6 \mu \mathrm{M}$ and IgGs were immobilized to a RU of $\sim 400-500$. The antigen for V1V2 region DH827, RhDH827, and RM DH614.2 was a synthetic V2 peptide (gp120 residues 167-184) in a concentration range of $12.5-50 \mu \mathrm{M}$ and IgGs were immobilized to a RU of $\sim 600$. Sensorgrams were corrected by subtraction of the corresponding blank channel and buffer background and normalized to a Rmax of $100 \mathrm{RU}$ for curve fitting purposes. Kinetic constants were determined using a 1:1 Langmuir binding model with the BIAevaluation software (GE Healthcare). Goodness of fit of the curves were evaluated by the $\mathrm{Chi}^{2}$ of the fit with a value below 3 considered as being acceptable (based upon use of a Rmax = $100 \mathrm{RU})$.

\section{Crystallization, Data Collection and Structure Solution}

Crystals were initially grown from commercial crystallization screens (Molecular Dimensions Proplex Eco and Rigaku precipitant synergy) and later optimized to produce crystals suitable for data collection by the hanging drop vapor diffusion method. C1C2 Cluster A region RhDH677.3 complex crystals were grown from 20\% PEG 4000 and $0.1 \mathrm{M}$ sodium citrate $\mathrm{pH}$ 4.5 and V1V2 region RhDH827 complex crystals were grown from $16.75 \%$ PEG 3350, 10.05\% isopropanol, and $0.2 \mathrm{M}$ ammonium citrate/citric acid $\mathrm{pH}$ 4.5. Crystals were briefly soaked in crystallization buffer supplemented with 20\% MPD (2-Methyl-2,4-pentanediol) and flash frozen in liquid nitrogen prior to data collection.

Diffraction data for the RhDH677.3 complex were collected at the Stanford Synchrotron Radiation Light Source (SSRL) beamline $12-2$ on a Dectris Pilatus $6 \mathrm{M}$ area detector and diffraction data for the RhDH827 complex were collected at the National Synchrotron Light Source II (NSLS-II) beamline 17ID-2 on a Dectris Eiger $16 \mathrm{M}$ area detector. All data were processed and reduced with HKL2000 (36) or imosflm and scala from the CCP4 suite (37). Structures were solved by molecular replacement with PHASER from the CCP4 suite (37) based on the coordinates of the human DH677.3 complex for the RhDH677.3 complex (PDB ID 6MFP) and the macaque Fab structure of RM JR4 for the RhDH827 complex (PDB ID
4RFE). Refinement was carried out with Refmac (37) and/or Phenix (38) and model building was done with COOT (37). Data collection and refinement statistics are shown in Table $\mathbf{1 .}$

\section{Structure Validation and Analysis}

Ramachandran statistics were calculated with MolProbity and illustrations were prepared with Pymol Molecular graphics (http://pymol.org). The processed data and final model for the RhDH677.3 complex are deposited in the PDB with accession number $7 \mathrm{~N} 8 \mathrm{Q}$ and those for the RhDH827 complex are deposited with accession number 7N0X.

\section{Surface Plasmon Resonance Affinity Measurements of FcyR Binding}

The affinity of IgG variants for RM and human Fcy receptors (Fc $\gamma R s$ ) were measured as previously described (23). Briefly, the antibodies were immobilized on a medium density carboxymethyldextran sensor (Xantec Bioanalytics, CMD200M) using a Continuous Flow Microspotter (Carterra) and carbodiimide chemistry. The soluble analyte consisted of dilutions of receptor beginning at $20 \mu \mathrm{M}$ and diluted by 1:3 over an 8-point series. Association and dissociation were measured for 5 minutes each on an imaging-based surface plasmon resonance (SPRi) instrument (IBIS Technologies, MX96). The results were analyzed in Scrubber 2 (BioLogic Software) using a first-order kinetic model to determine the equilibrium dissociation constant.

\section{HIV-1 IMC-Infection of CEM.NKR CCR5 $_{\text {Cells }}$}

The infection of cells was performed as previously reported (43). Briefly, R5 tropic HIV-1 IMC virus stocks (1086.C, CH505, SF162) were titrated to determine the input required for optimal viral gene expression within $72 \mathrm{~h}$ post-infection of CEM.NKR $\mathrm{CCR}_{5}$ cells as measured by intra-cellular p24 expression. Stocks were used to infect $2 \times 10^{6}$ cells with each IMC by incubation with the appropriate dose for $30 \mathrm{~min}$ at $37^{\circ} \mathrm{C}$ and $5 \% \mathrm{CO}_{2}$ in the presence of DEAE-Dextran $(7.5 \mu \mathrm{g} / \mathrm{mL})$. The cells were subsequently resuspended at $0.5 \times 10^{6} / \mathrm{mL}$ and cultured for 2 days in complete medium containing $7.5 \mu \mathrm{g} / \mathrm{mL}$ DEAE-Dextran. On assay day, the infection was monitored by measuring the frequency of cells expressing intracellular p24. The assays performed using the IMC-infected target cells were considered reliable if the percentage of viable p24+ target cells on assay day was $\geq 20 \%$. Assay data generated using infected cells was normalized to the $\%$ of target cells positive for intracellular p24.

\section{SHIV-Infection of A66 Cells}

The infection of A66 cells [SupT1 cells (non-BC7 variant variant (44) that have been stably transfected to express both rhesus CD4 and rhesus CCR5 receptors after knockout of endogenous human CXCR4 and CD4 (45), provided by James Hoxie, University of Pennsylvania, Philadelphia, PA] was conducted as described previously (46). Briefly, R5 tropic SHIV virus stocks SF162.P3 (32) grown in human PBMCs, or $\mathrm{CH} 505.375 \mathrm{H}$ (47) and $1157(\mathrm{QNE}) \mathrm{Y} 173 \mathrm{H}$ (48) grown in 
TABLE 1 | Data collection and refinement statistics.

\begin{tabular}{|c|c|c|}
\hline & $\begin{array}{l}\text { RhDH677.3 Fab-M48U1- } \\
\text { gp120 }_{93 т H 057} \text { core }_{e}\end{array}$ & $\begin{array}{c}\text { RhDH827 Fab-V2 } \\
\text { peptide }\end{array}$ \\
\hline \multicolumn{3}{|l|}{ Data collection } \\
\hline Wavelength, $\AA$ & 0.979 & 0.979 \\
\hline Space group & $\mathrm{P} 2_{1}$ & $\mathrm{C} 2$ \\
\hline \multicolumn{3}{|l|}{ Cell parameters } \\
\hline$a, b, c, \AA$ & $99.2,82.7,111.9$ & $81.6,71.9,87.7$ \\
\hline$\alpha, \beta, \gamma^{\circ}$ & 90, 112.0, 90 & $90,111.5,90$ \\
\hline Complexes/a.u. & 2 & 1 \\
\hline Resolution, $(\AA ̊)$ & $50-2.9(2.95-2.9)$ & $50-2.0(2.1-2.0)$ \\
\hline \multicolumn{3}{|l|}{ \# of reflections } \\
\hline Total & 77,728 & 126,613 \\
\hline Unique & $31,091(1,645)$ & $31,034(4,384)$ \\
\hline $\mathrm{R}_{\text {merge }}{ }^{a}, \%$ & $10.6(62.7)$ & $9.5(47.4)$ \\
\hline $\mathrm{R}_{\text {pim }}{ }^{\mathrm{b}}, \%$ & $7.8(46.7)$ & $5.3(26.5)$ \\
\hline $\mathrm{CC}_{1 / 2}{ }^{\mathrm{C}}$ & $0.98(0.71)$ & $0.99(0.81)$ \\
\hline Wilson $B_{\text {factor }}\left(1 / \AA^{2}\right)^{d}$ & 64 & 27.6 \\
\hline $\mathrm{l} / \sigma$ & $9.6(1.1)$ & $5.3(1.5)$ \\
\hline Completeness, \% & 82.7 (86.0) & $99.5(98.2)$ \\
\hline Redundancy & $2.5(2.5)$ & $4.0(4.0)$ \\
\hline \multicolumn{3}{|l|}{ Refinement } \\
\hline \multicolumn{3}{|l|}{ Statistics } \\
\hline Resolution, $\AA$ & $50.0-2.9$ & $50.0-2.0$ \\
\hline $\mathrm{R}^{\mathrm{e}}, \%$ & 25.5 & 18.1 \\
\hline $\begin{array}{l}\mathrm{R}_{\text {free }}, \% \\
\text { \# of atoms }\end{array}$ & 29.6 & 20.9 \\
\hline Protein & 11,758 & 3,361 \\
\hline Water & 15 & 273 \\
\hline Ligand/lon & 284 & 7 \\
\hline \multicolumn{3}{|l|}{ Overall B value $(\AA)^{2}$} \\
\hline Protein & 71 & 37 \\
\hline Water & 42 & 43 \\
\hline Ligand/Ion & 69 & 61 \\
\hline \multicolumn{3}{|l|}{$\begin{array}{l}\text { Root mean square } \\
\text { deviation }\end{array}$} \\
\hline Bond lengths, ^ & 0.007 & 0.007 \\
\hline Bond angles, ${ }^{\circ}$ & 1.6 & 0.9 \\
\hline \multicolumn{3}{|l|}{ Ramachandran ${ }^{9}$} \\
\hline favored, \% & 80.2 & 96.1 \\
\hline allowed, \% & 13.9 & 3.0 \\
\hline outliers, \% & 5.9 & 0.9 \\
\hline PDB ID & $7 \mathrm{~N} 8 \mathrm{Q}$ & $7 \mathrm{NOX}$ \\
\hline
\end{tabular}

Values in parentheses are for highest-resolution shell.

${ }^{a} R_{\text {merge }}=\Sigma \mid l-\langle|>||\Sigma|$, where $I$ is the observed intensity and $\langle 1\rangle$ is the average intensity obtained from multiple observations of symmetry-related reflections after rejections.

${ }^{b} R_{\text {pim }}=$ as defined in (39).

${ }^{c} C_{1 / 2}=$ as defined by Karplus and Diederichs (40).

${ }^{d}$ Wilson $B_{\text {factor }}$ as calculated in (41).

${ }^{e} R=\Sigma|| F_{o}|-| F_{c} \| \Sigma \Sigma\left|F_{o}\right|$, where $F_{o}$ and $F_{c}$ are the observed and calculated structure factors, respectively.

${ }^{f} R_{\text {free }}=$ as defined by Brünger (42).

${ }^{g} \mathrm{Cal}$ culated with MolProbity.

Rhesus PBMCs were titrated to determine the input required for optimal viral gene expression within $72 \mathrm{~h}$ post-infection of A66 cells as measured by intracellular p27 expression. A66 cells $(1 \times$ $10^{6}$ cells per infection) were incubated for 4 hours at $37^{\circ} \mathrm{C}$ and $5 \% \mathrm{CO}_{2}$ in the presence of DEAE-Dextran $(10 \mu \mathrm{g} / \mathrm{mL}$, Sigma Aldrich). The cells were subsequently resuspended at $0.33 \times 10^{6} /$ $\mathrm{mL}$ and cultured for 3 days in complete medium containing 10 $\mu \mathrm{g} / \mathrm{mL}$ DEAE-Dextran. On assay day, infection was monitored by measuring the frequency of cells expressing intracellular p27. The assays performed using the SHIV-infected target cells were considered reliable if the percentage of viable p27+ target cells on assay day was $\geq 10 \%$. Assay data generated using infected cells was normalized to the frequency of live target cells positive for intracellular p27.

\section{Infected Cell Antibody Binding Assay (ICABA)}

ICABA was used to evaluate the ability of mAbs to bind Env on the surface of HIV- or SHIV-infected cells. HIV-infected CEM.NKR.CCR5 cells and SHIV-infected A66 cells were obtained as described above. Cells incubated in the absence of virus (mock infected) were used as a negative control. Infected and mock infected cells were washed in PBS, dispensed into 96well V-bottom plates at $2 \times 10^{5}$ cells/well and incubated with $1 \mu \mathrm{g} / \mathrm{mL}$ of indicated mAbs for 2 hours at $37^{\circ} \mathrm{C}$. After two washes with $250 \mu \mathrm{L} /$ well WB, the cells were stained with vital dye (Live/Dead Fixable Aqua Dead Cell Stain, Invitrogen) to exclude nonviable cells from subsequent analysis. Cells were washed with wash buffer (5\%FBS in PBS) and stained with anti-CD4-PerCPCy5.5 (clone OKT-4 for CEM.NKR.CCR5 cells or clone Leu-3 for A66 cells; BD Biosciences) to a final dilution of 1:20 in the dark for $20 \mathrm{~min}$ at room temperature (RT). Cells were then washed again, and permeabilized using Cytofix/Cytoperm (BD Biosciences). Anti-p24 antibody (clone KC57-RD1; Beckman Coulter, 1:100 dilution in 1x Cytoperm Solution, BD Biosciences) and a secondary FITC-conjugated antibody (goat anti-human $\operatorname{IgG}(\mathrm{H}+\mathrm{L})$-FITC, KPL, final dilution of 1:100 or Goat Anti Rh IgG(H+L)-FITC, Southern Biotech, final dilution of 1:200) for CEM.NKR.CCR5 cells; anti-p27 antibody (WNPRC Immunology Services, 1:500 dilution in 1x Cytoperm Solution, BD Biosciences) and a secondary PE-conjugated antibody (goat anti-human Ig Fc-PE, eBioscience, San Diego, CA., final dilution of 1:400 or Goat Anti-Rh IgG(H+L)-PE, Southern Biotech, final dilution of 1:200) were added to each well and incubated in the dark for $25 \mathrm{~min}$ at $4^{\circ} \mathrm{C}$. Cells were washed three times with Cytoperm wash solution and resuspended in PBS-1\% paraformaldehyde. The samples were acquired within 24 hours using a BD Fortessa cytometer. A minimum of 50,000 total events was acquired for each analysis. Gates were set to include singlet and live events. Data analysis was performed using FlowJo 9.6.6 software (BD Biosciences). Final data represents the frequency of infected cells $(\mathrm{Ab}+\mathrm{p} 24+$ or $\mathrm{Ab}+\mathrm{p} 27+)$ and FITC MFI or PE MFI of binding of IgG mAbs to HIV Env, after normalization by subtraction of the frequency or MFI observed for cells stained with the secondary antibody alone.

\section{Renilla Luciferase-Based ADCC Assay}

The LucR-based ADCC assay was conducted as described by Pollara et al. (49). The day prior to the ADCC assay, cryopreserved PBMCs to be used as effectors in the assay were thawed in R10 [RPMI medium supplemented with 10\% Fetal Bovine Serum (FBS)], counted and assessed for viability and resuspended in R10 overnight. On the day of the assay, infected CEM.NKR $\mathrm{CCR}_{\text {5 }}$ cells were counted, assessed for viability (viability was $\geq 80 \%$ to be used in the assay) and the concentration was adjusted to $2 \times 10^{5}$ viable cells $/ \mathrm{mL}\left(5 \times 10^{3}\right.$ 
cells/well). PBMCs were then counted, assessed for viability, pelleted and resuspended in the infected CEM.NKR $\mathrm{CCR}_{5}$ cells at a concentration of $6 \times 10^{6} \mathrm{PBMCs} / \mathrm{mL}\left(1.5 \times 10^{5} \mathrm{PBMCs} /\right.$ well $)$ (effector: target cell ratio of 30:1). The mAbs starting at $50 \mu \mathrm{g} / \mathrm{mL}$ were serially diluted 1:5. The effector/target cell mix and antibody dilutions were plated in opaque 96-well half-area plates, centrifuged at $300 \mathrm{x}$ g for $1 \mathrm{~min}$ after $30 \mathrm{~min}$ incubation at room temperature, and then incubated for $5.5 \mathrm{hrs}$ at $37^{\circ} \mathrm{C}$, $5.5 \% \mathrm{CO}_{2}$ to allow ADCC-mediated cell lysis to proceed. After 5.5 hrs, ViviRen substrate (Promega) was diluted 1:500 in R10 and added 1:1 to the assay wells. The substrate generates luminescence only in live, infected cells; not in dead or lysed cells. The final readout was the luminescence intensity generated by the presence of residual intact target cells that have not been lysed by the effector population in the presence of ADCCmediating antibodies. The percentage of specific killing was calculated using the formula

$\%$ specific killing

$$
=\frac{\text { RLU of target }+ \text { effector well }- \text { RLU of test well }}{\text { RLU of target }+ \text { effector well }} \times 100
$$

In the analysis, the RLU of the target + effector wells represent lysis by effector cells in the absence of any source of antibody. Synagis, a human mAb specific for respiratory syncytial virus (50), and DSP_Rh, a macaque mAb specific for desipramine (DSPR1) from the nonhuman primate reagent resource (www. nhpreagents.org), were used as negative controls.

\section{ADCC-GranToxiLuc Assay}

ADCC activity was detected according to the previously described ADCC-GranToxiLux (GTL) procedure using recombinant SHIV.1157QNE(Y173H) gp120 coated CEM. $\mathrm{NKR}_{\mathrm{CCR} 5}$ as target cells and cryopreserved PBMC from a HIVseronegative donor as effector cells (51) with E:T ratio of 30:1 The mAbs starting at $50 \mu \mathrm{g} / \mathrm{mL}$ were serially diluted $1: 5$. The results of the GTL assay were considered positive if \% Granzyme $\mathrm{B}$ activity after background subtraction was $\geq 8 \%$ for the infected target cells.

\section{ADCC AUC}

The specific killing activities in the ADCC assay were summarized for each subject and antigen by computing the area under the dilution curve (AUC) which was calculated from dilution curves using non-linear trapezoidal rule. Nonspecific killing activities mediated by negative control mAbs, Synagis or DSP_Rh, were subtracted from the corresponding human or rhesus mAbs prior to AUC calculation.

\section{Antibody Dependent Cellular Phagocytosis (ADCP) and Antibody Dependent Neutrophil Phagocytosis (ADNP)}

ADCP was performed as previously described $(52,53)$. Briefly, ADCP was quantified by covalently binding biotinylated SHIV 1157(QNE)Y173H gp120 Env glycoprotein $(1 \mu \mathrm{g}$ gp120/ $\mu \mathrm{L}$ of bead) to $9 \times 10^{5}$ neutravidin fluorescent beads (ThermoFisher, F8776). Beads were then incubated with monoclonal antibodies for 2 hours to form immune complexes. THP-1 cells (ATCC, TIB-202) pre-treated with anti-CD4 (Biolegend, 344602) were then added to the immune complexes (25,000 cells/well) and spinoculated at $4^{\circ} \mathrm{C}$. Following spinoculation, the cells were incubated at $37^{\circ} \mathrm{C}$ for 1 hour and fixed with $2 \%$ paraformaldehyde. The fluorescence of the cells was detected using flow cytometry (BD LSRFortessa). To calculate phagocytosis scores a cutoff was first assigned based on the 95th percentile of the no-antibody control (PBS only). The magnitude of the ADCP immune response (ADCP score) was calculated by multiplying the mean fluorescence intensity (MFI) and frequency of phagocytosis-positive cells and dividing by the MFI and frequency of the bead-positive cells in an antibodynegative (PBS) control well. Control antibodies were selected based positive binding to SHIV 1157(QNE) gp120 antigen. CH31_IgG3 mAb (Catalent), and CH235_12_IgA (54) (kindly provided by Huaxin Liao, Mattia Bonsignori, and Bart Haynes, Duke University) HIV specific, CD4bs broadly neutralizing antibodies (55), were included as positive controls and the non-HIV-specific CH65 IgG1 mAb (Catalent) (56) was included as a negative control. ADNP was performed as described for ADCP with the following modification: HL-60 cells (ATCC, CCL-240) pre-treated with DMSO for 5 days (57) were used as effector cells. The IgA antibody positive control was utilized to confirm that differentiation of the HL-60 cells to be neutrophil-like with expression of $\mathrm{FcR}$ alpha engagement. Positivity cutoff was 2.2 calculated from the mean +3 standard deviations of the negative control.

\section{Infectious Virion Capture Assay (IVCA) (Column)}

Infectious virion capture assay (IVCA) was measured as previously described $(53,58-60)$. Briefly, the IVCA method utilizes a Protein G column based capture of Ig-virion immune complexes allowing for the analysis of infectious virions (TZM-bl infectivity assay). Briefly, antibodies were mixed with SHIV1157 (QNE)Y173H (kindly provided by Abraham Pinter, Rutgers New Jersey Medical School) at final concentration of $25 \mu \mathrm{g} / \mathrm{ml}(200 \mu \mathrm{l}$ volume) to form Ab-virion immune complexes (IC), which were passed through a protein G column. The infectivity of the flowthrough was measured by a TZM-bl infection assay. The percentage of captured infectious virions (iVirion) were calculated as follows: iVirion $=[(100-$ flow-through infectivity)/(virus no-Ab infectivity)] x 100. HIVIG polyclonal human sera (NIH HIV Reagent Program) was included as a positive controls and the non-HIV-specific CH65 IgG1 mAb (Catalent) (61) was included as a negative control. Positivity cutoff was $15.6 \%$ calculated from the mean +3 standard deviations of the negative control.

\section{RESULTS}

\section{Engineering Rhesusized Variants of Human mAbs}

Three HIV-1 specific human antibodies, DH677.3, DH827, and $7 \mathrm{~B} 2$, were converted to macaque versions, i.e. rhesusized, with the aid of both the macaque genome and structural information 
about each antibody's epitope (30-33). For clarity rhesusized versions of antibodies will begin with an $\mathrm{Rh}$ in the name and native macaque antibodies will have an RM designation; human antibodies will have no designation to be consistent with the names assigned to them by the literature. Sequence changes were kept to a minimum to maintain specificity and reduce immunogenicity. The schematic of how theses rhesusized variants were made is shown in Figure 1. First, the inferred macaque germline gene closest in sequence to the human antibody was identified. At positions where the equivalent position in the macaque germline sequence could not be determined the corresponding amino acid from the human sequence was used. Complementary determining regions (CDRs) were then changed to that of the human antibody. When structural information about the epitope in human showed that residues outside of the CDRs were involved in binding antigen, those human contact residues were introduced into the macaque germline sequence. The rhesusized antibody therefore consists of macaque framework sequences modified to be human only at positions that are part of the paratope and human CDR sequences with fully macaque constant regions (the resulting rhesusized sequences are shown in Figure S1). Altogether, generation of Rh7B2 $\mathrm{V}_{\mathrm{H}}$ and $\mathrm{V}_{\mathrm{L}}$ required 18 changes in sequence for heavy chain framework residues and 17 changes in framework residues for the light chain relative to the human 7B2; one additional heavy chain change relative to the macaque sequence was required due to a framework epitope contact and one light chain change due to a missing macaque residue at position 65 in the germline sequence. Generation of RhDH677.3 $\mathrm{V}_{\mathrm{H}}$ and $\mathrm{V}_{\mathrm{L}}$ required 9 heavy chain and 7 light chain changes in sequence relative to the human DH677.3 as well as one heavy chain change at position 6 due to a missing residue in the macaque germline sequence. Generation of RhDH827 $\mathrm{V}_{\mathrm{H}}$ and $\mathrm{V}_{\mathrm{L}}$ required 11 heavy and 7 light chain framework changes in sequence. The heavy chain $\mathrm{C}_{\mathrm{H}}\left(\mathrm{C}_{\mathrm{H}} 1\right)$ and $\mathrm{Fc}\left(\mathrm{C}_{\mathrm{H}} 2\right.$ and $\left.\mathrm{C}_{\mathrm{H}} 3\right)$ of all the antibodies were fully macaque with 27 changes and 3 inserted glycine residues relative to the human IgG1 ( $91 \%$ overall identity). $\mathrm{C}_{\mathrm{L}}$ differences varied for each antibody depending on whether the light chain was kappa, RhDH677.3 and Rh7B2, or lambda, RhDH827. RhDH677.3 and Rh7B2 had 17 changes in their $\mathrm{C}_{\mathrm{L}}$ kappa light chains relative to their human counterparts (84.1\% identity) and $\mathrm{RhDH} 827$ had 12 changes in its $\mathrm{C}_{\mathrm{L}}$ relative to its lambda equivalent ( $88.6 \%$ identity). Therefore, excluding CDRs, the Rh7B2 Fab was $78.4 \%$ identical in sequence to the $7 \mathrm{~B} 2$ Fab and $98.8 \%$ identical in sequence to the inferred macaque germline gene, the RhDH677.3 Fab was 90.4\% identical in sequence to the DH677.3 Fab and $99.4 \%$ identical to its macaque germline sequence, and the RhDH827 Fab was $88 \%$ identical to the DH827 Fab and $100 \%$ identical to its macaque germline sequence.

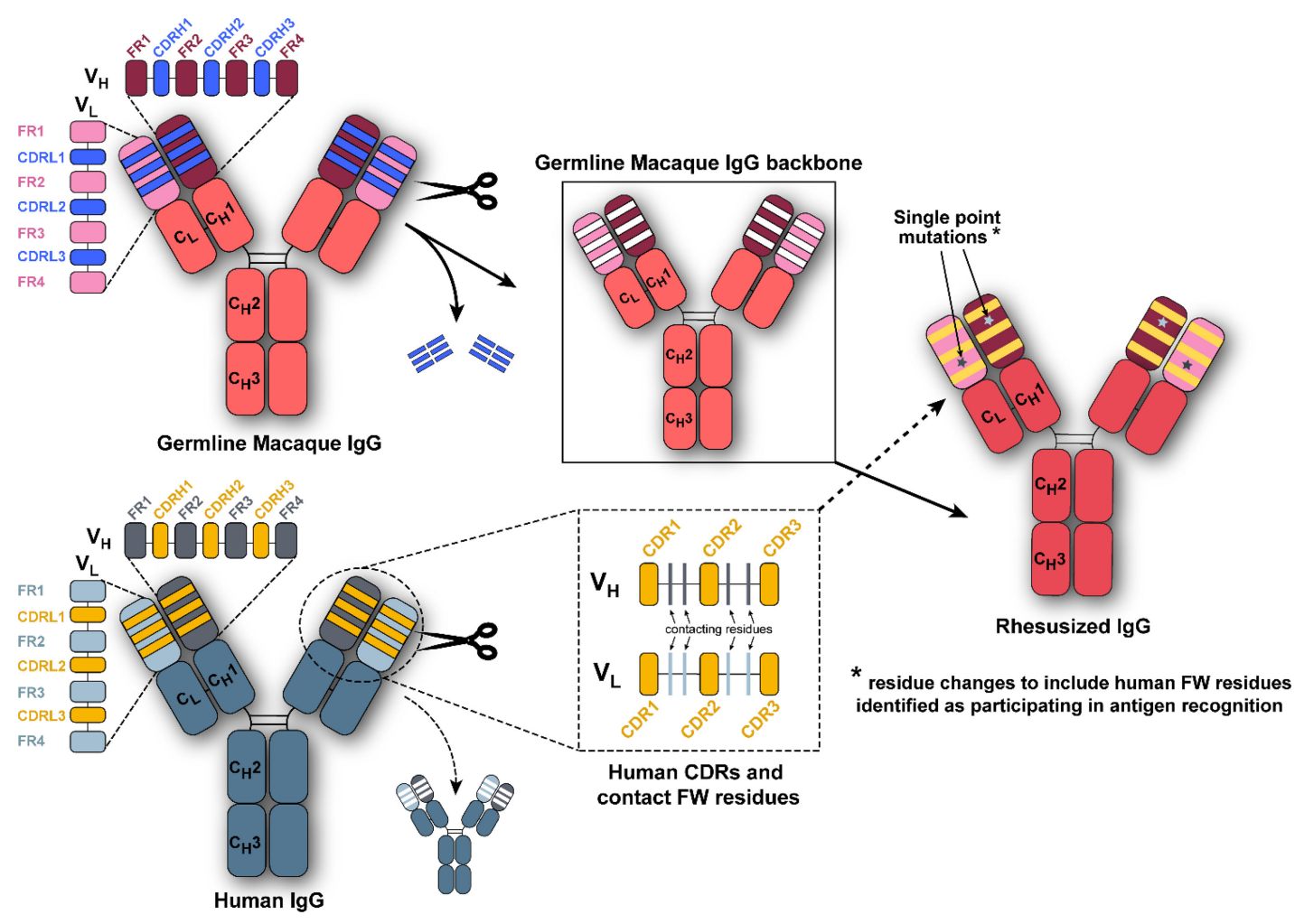

FIGURE 1 | Composition scheme for rhesusized antibody engineering. We grafted the human complementary-determining regions (CDRs) and any framework (FW) residues contributing to antigen binding when structural data was available of the parental human monoclonal antibody (bottom left panel) onto the macaque germline framework and antibody backbone (top left panel) to generate the rhesusized antibody (right panel). 


\section{Rhesusized mAb Variants Bind to RM and Human Fc $\gamma$ Receptors With Similar Binding Affinities to Those of RM Origin}

Proper rhesusization should result in an antibody variant that preserves its structural integrity and both the binding properties mediated by the Fc of the equivalent RM IgG subclass and those mediated by the Fab (i.e. epitope specificity and binding interface) of the parent human mAb. Accordingly, rhesusized $\mathrm{mAb}$ variants were generated in a RM IgG1 backbone to match the original parent human IgG1 backbone (Figures $\mathbf{1}$ and $\mathbf{S 1}$ ). To validate this design we tested the Fc binding properties of our rhesusized variants to receptors expressed on effector cells involved in Fc-effector functions to see if they were comparable to mAb IgG1s of RM origin. We show in Figure 2, Table S1 and Figure S2 the SPR binding kinetics of RhDH677.3, Rh7B2 and RhDH827 to both rhesus and human low affinity FcyRs measured with IgG immobilized on a sensor chip and Fc $\gamma \mathrm{R}$ in solution. Two antibody specificities were used as controls of RM origin. The antibody used as a control for an epitope from the $\mathrm{C} 1 \mathrm{C} 2$ Cluster A region was RM JR4, a mAb derived from the peripheral blood B cells of a rhesus macaque infected with the simian-human immunodeficiency virus (SHIV) KB9 mutant that contains gp41 glycosylation site deletions (62). Antibodies used as a control for an epitope in the V1V2 region were clonal variants of RM DH614 (RM DH614.1, RM DH614.2 and RM DH614.3), mAbs isolated from a RM vaccinated with the vaccine regimen used in RV144 (63). Among the receptors tested were polymorphic variants 1, 2 and 4 of

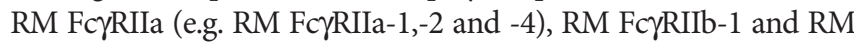
Fc $\gamma$ RIIIa-1 and 3 as described in (23). Human receptors tested included high and low affinity variants of Fc $\gamma$ RIIa and FcyRIIIa and a low affinity inhibitory receptor Fc $\gamma$ RIIb. Interestingly, binding affinities of the rhesusized IgG variants to all low affinity RM receptors tested were in the range of binding affinities detected for IgG variants that were cloned directly from an RM host with no statistical difference between the groups. The only statistical difference between the rhesusized and RM antibody groups was seen in an unpaired T-test for the low affinity allelic variant of human FcyRIIa(R131) with $\mathrm{P}$ value $=0.0173$. No significant differences in affinities to the other human Fc $\gamma$ receptors were detected This indicates that the engineered rhesus Fc backbone is properly folded and the variants fully preserve the Fc-binding properties of an IgG1 of RM origin to all $\mathrm{RM} F \mathrm{~F} \gamma$ receptors

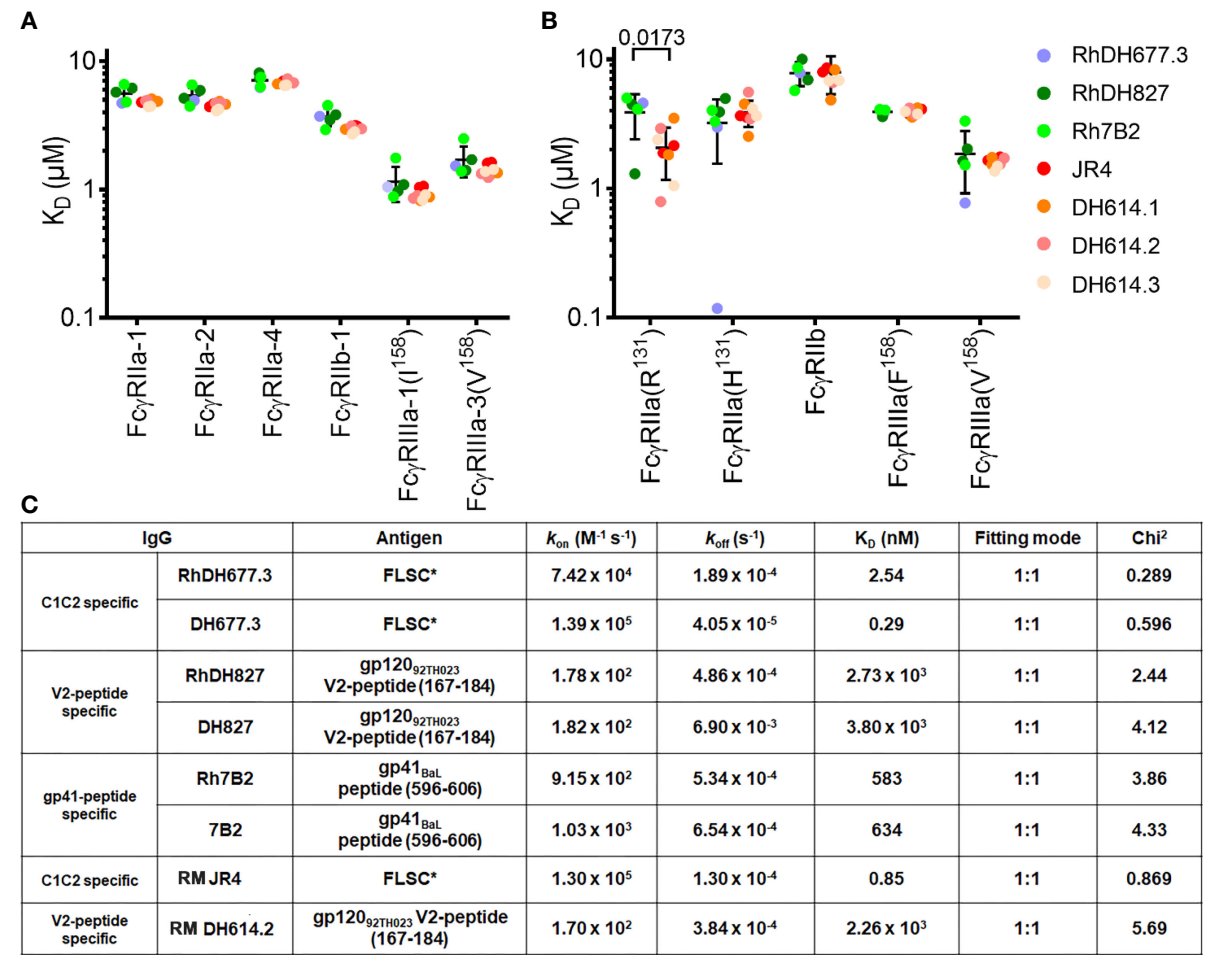

FIGURE 2 | Affinity of rhesusized variants for low affinity receptors. Binding affinities of (A) rhesus and (B) human FcyRs. Equilibrium binding constants (K $\left.K_{D}\right)$ measured by SPR for common rhesus and human FcyR allotypes. Data show individual replicates, and error bars denote the standard deviation. Data are representative of 2 independent experiments. RhDH677.3, RhDH827, and Rh7B2 are rhesusized mAbs. RM JR4 (62), RM DH614.1, RM DH614.2, and RM DH614.3 (63) are mAbs originally isolated from a RM vaccinated with the vaccine regime used in RV144. The P-value for an unpaired T-test for rhesusized and RM mAbs is shown above the compared pair. (C) SPR binding kinetics for rhesusized (RhDH677.3, RhDH827, and Rh7B2) and human [DH677.3 (30), DH827 (31) and 7B2 (32)] mAb pairs. RM JR4 (62) and RM DH614.2 (63), mAbs originally isolated from RM, were used as controls. FLSC, a covalent dimer of gp120 $\mathrm{BaL}_{\mathrm{L}}$ and domain 1 and 2 of CD4 (35) was used as antigen for C1C2 Cluster A specific mAbs RhDH677.3, DH677.3 and control JR4, gp12092THO23 V2 peptide (residues 167-184) was used as antigen for V1V2 region mAbs RhDH827, DH827 and control RM DH614.2, and gp41 BaL peptide (residues 596-606) was used as antigen for gp41 region specific mAbs Rh7B2 and 7B2. 
involved in Fc-effector mechanisms and all but one human low affinity $\mathrm{Fc} \gamma$ receptors. The rhesusized $\mathrm{mAb}$ variants therefore preserve the RM IgG1 structure with variable regions $(\mathrm{V})$ and antigen-binding characteristics of the parent human mAb. Rhesusized mAb variants bind to RM and human Fcy receptors with similar binding affinities to those of RM origin.

\section{Rhesusized mAb Variants Bind to Antigen With Similar Binding Affinities to Those of Human Origin}

We also examined the integrity and binding properties of the Fab to see if the recognition of HIV-1 Env was preserved in the variants as compared to their human counterparts. First, we used surface plasmon resonance analyses (SPR) to test the biding properties of human and rhesusized antibody pairs to appropriate antigens. For CD4 inducible (CD4i) antibodies (e.g. RM JR4 and DH677.3) we used full length single chain (FLSC), a covalent dimer of gp $120_{\mathrm{BaL}}$ and CD4 that specifically exposes CD4i epitopes (35). For antibodies specific for linear epitopes within the V2 loop (e.g. DH827 and D614 lineage) or gp41 (e.g. 7B2) we used the peptides that were used in cocrystallization studies $(30,32)$. As shown in Figure $\mathbf{2 B}$ and Figure S3 all pairs tested with the exception of DH677.3 had identical or highly similar binding kinetics; RhDH677.3 had an approximately 8 -fold lower $\mathrm{K}_{\mathrm{D}}$ than human DH677.3 mainly due to an increase in the off-rate. This difference in affinity could be result of slight differences in the paratope, discussed in more detail below, or the result of removal of a glycan attached to $\mathrm{Asn}^{72}$ of the heavy chain sequence (Asp ${ }^{72}$ in RhDH677.3); this glycan sits outside of the paratope but could affect the affinity by interacting with the gp120 N-terminus.

Next, to more carefully examine the molecular details of the antibody-antigen interface and to assess if $\mathrm{mAb}$ epitopes were fully preserved in the rhesusized variants we solved crystal structures of both the RhDH677.3 and RhDH827 Fabs in complex with their respective cognate Env antigens (Table 1). Shown in Figure 3 is the structure of RhDH677.3 Fab in complex with gp120 ${ }_{93 \mathrm{TH} 057}$ core $_{\mathrm{e}}$ and the CD4 peptide mimetic M48U1. The parent of RhDH677.3, DH677.3, is a Cluster A specific antibody isolated from a RV305 vaccinee, a follow up study of a subset of RV144 vaccinees with delayed boosting using RV144 immunogens $(31,64)$ with a similar epitope footprint to RV144 mAbs (65). The RhDH677.3 Fab-gp120 ${ }_{93 \text { TH057 }}$ core $_{\mathrm{e}}$-M48U1 complex (Figure 3A) crystallized in space group $\mathrm{P} 22_{1}$ with two complexes in the asymmetric unit and diffracted to $2.9 \AA$ resolution (Table 1). The CD4 mimetic M48U1 was only found bound to one of the two complexes in the asymmetric unit due to clashes with neighboring complexes in the crystal. The gp120 in the second complex was therefore more disordered and less like the typical CD4-bound gp120 conformation present in the first complex of the asymmetric unit. However, within the region corresponding to the antibody-gp120 interface both copies of the complex were still highly similar with nearly identical conformations (Figure S4). Since the RV305 mAb DH677.3 also crystallized with two complexes in the asymmetric unit but with M48U1 bound for both copies (31), we only used the first complex (with M48U1 bound) from the RhDH677.3 Fab-gp120 ${ }_{93 \text { TH057 }}$ core $\mathrm{e}_{\mathrm{e}}$ M48U1 complex crystal structure for comparison (Table S2). Values from the DH677.3 structure on the other hand, represent an average of those from both copies.

RhDH677.3, similar to its progenitor DH677.3, binds at the base of the 7 -stranded $\beta$-sandwich of the gp120 inner domain with contributions from the inner domain mobile layers 1 and 2 (Figure 3). The total buried surface area (BSA) for the RhDH677.3-gp120 interface in the complex is $1800 \AA^{2}$ which is very similar to the BSA for the interface contributed by its human counterpart, DH677.3, $1894 \AA^{2}$ (Table S2). RhDH677.3 antibody-gp120 contacts involve residues in layer 1 (residues 53, 71-80 and 82), layer 2 (residues 219-222), and the 7-stranded $\beta$ sandwich (residues 84, 223-224, 244-246, and 491-492) (Figure 3C) almost entirely mimicking the antigen footprint of DH677.3. The only noticeable difference with its human counterpart is that the RhDH677.3 Fab-gp120 interface lacks two additional gp120 residues buried in the DH677.3 Fab-gp120 interface, i.e. Ala ${ }^{60}$ and $\mathrm{Glu}^{87}$. Overall, the lower total BSA for the macaque RhDH677.3 complex is mostly a result of slightly lower BSA values in most gp120 regions (Figures 3B-D, Table S2). The macaque complex buries $530 \AA^{2}$ of the gp120 inner domain layer $1,120 \AA^{2}$ of layer 2, and $226 \AA^{2}$ of the 7-stranded $\beta$ sandwich, while the human structure buries an average of $540 \AA^{2}$ of layer $1,133 \AA^{2}$ of layer 2 , and $261 \AA^{2}$ of the 7 -stranded $\beta$ sandwich. The added surface area for the human complex comes in part from additional contributions from light chain framework contacts near the N-terminus, slightly higher BSA values for CDRs H3 and L3, and framework residue differences between the human and macaque antibodies (Figure 4 and Figure S2). The framework residue changes include light chain framework region 1 which contains an alanine, $\mathrm{Ala}^{1}$, in the macaque germline sequence and an aspartic acid, $\mathrm{Asp}^{1}$, in the human sequence. $\mathrm{Ala}^{1}$ in the macaque sequence does not contact gp120 at all, while Asp $^{1}$ via its side chain makes main chain contacts to gp120 residues $\mathrm{Thr}^{71}, \mathrm{Cys}^{74}, \mathrm{Val}^{75}$, and $\mathrm{Pro}^{76}$ and side chain contacts with Pro $^{76}$ (Figure 3C),. This one residue difference largely accounts for the $31 \AA^{2}$ increase in BSA for this region (Figure $\mathbf{4 C}, \mathbf{D}$ ). The second is in the heavy chain framework region 3 which contains an aspartic acid, Asp ${ }^{72}$, in the macaque germline sequence that is not glycosylated but an asparagine, $\mathrm{Asn}^{72}$, in the human structure that is. This glycan sits outside of the antibody paratope on the edge of the $\beta$ sandwich and is not directly involved in binding in the 7stranded $\beta$-sandwich gp120 complex but could potentially make contact to the eighth strand in an 8 -stranded $\beta$-sandwich complex. One additional framework residue difference seems to have an indirect effect on the interface. In the macaque structure $\mathrm{Ser}^{31}$ in CDR $\mathrm{H} 1$ does not contribute to the interface, but in human structure $\mathrm{Ala}^{30}$ instead of $\mathrm{Thr}^{30}$ in framework region 1 allows $\mathrm{Ser}^{31}$ to contribute to the interface and the total BSA. In total these sequence differences help explain the $58 \AA^{2}$ greater gp120 BSA and the $36 \AA^{2}$ greater Fab BSA for the human complex as compared to the macaque complex. Despite the differences in the BSA values, the gp120 antigen complexes 
A
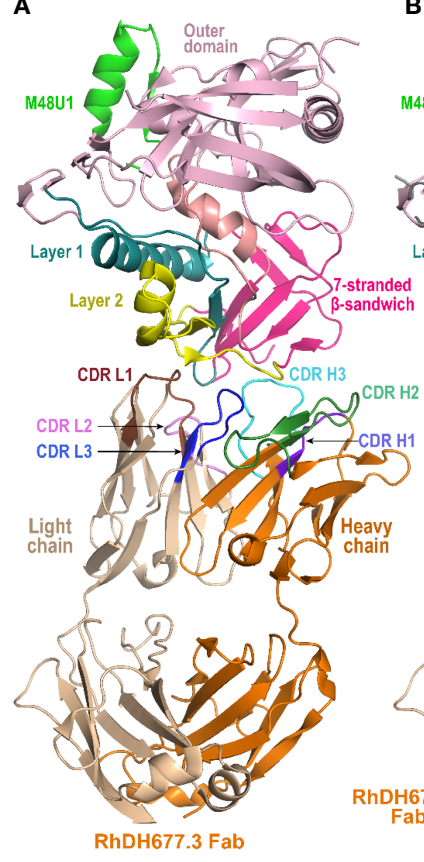

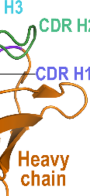

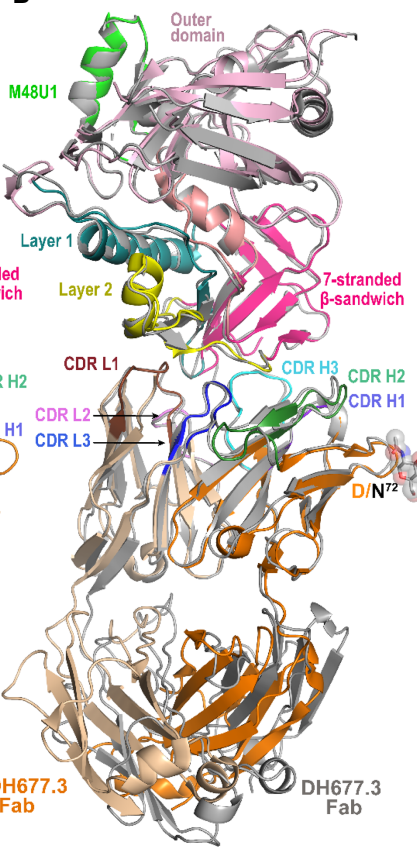

C

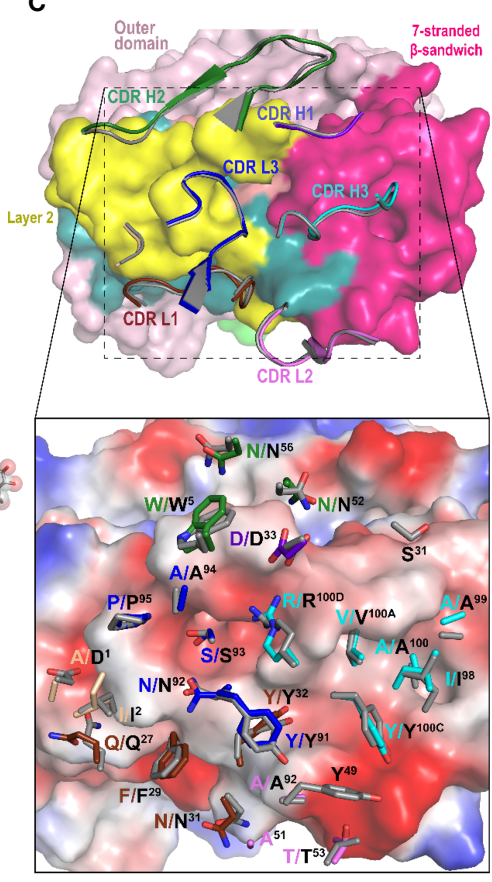

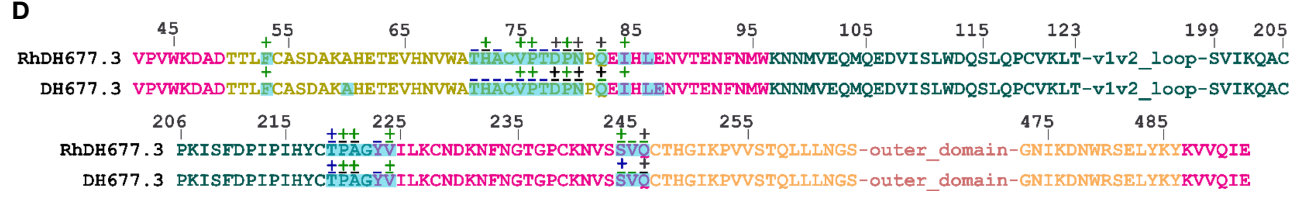

FIGURE 3 | Crystal structure of RhDH677.3 Fab-gp12093тн057 core - -M48U1 complex. (A) The overall structure of the complex is shown as a ribbon diagram. The light chain (LC) and heavy chain (HC) of the RhDH677.3 Fab are colored in wheat and orange, respectively. The complementary-determining regions (CDRs) of RhDH677.3 Fab are colored as following: CDR H1 is purple blue, CDR H2 is dark green, CDR H3 is cyan, CDR L1 is dark brown, CDR L2 is purple, and CDR L3 is blue. Outer domain of gp120 is light pink. Layers 1, 2 and the 7-stranded -sandwich of the inner domain are colored as green, yellow and magenta, respectively.

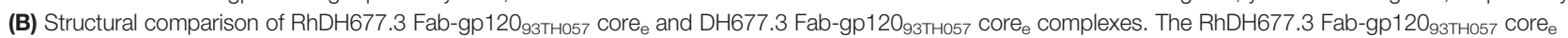
complex is colored as indicated in panel A and the DH677.3 Fab-gp120 ${ }_{937 H 057}$ core $_{e}$ complex is colored in gray. The complexes are superimposed based upon gp120 and the heavy and light chain variable $\left(\mathrm{V}_{\mathrm{H}}\right.$ and $\left.\mathrm{V}_{\mathrm{L}}\right)$ domains. The carbohydrate at position Asn ${ }^{72}$ of the $\mathrm{DH} 677.3 \mathrm{Fab}$ is shown as sticks. (C) The RhDH677.3

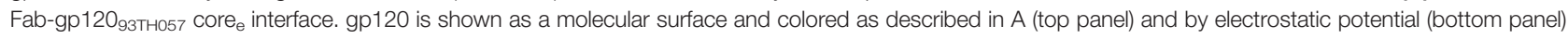
with red, blue and white representing negative, positive and neutral electrostatic potential, respectively. CDRs of RhDH677.3 Fab are shown as ribbons (top panel) and side chains of binding residues are shown as sticks (bottom panel). Binding residues of RhDH677.3 Fab are colored as in panel A and binding residues of DH677.3 Fab are colored in dark gray. (D) Contact residues of gp120 are mapped onto the gp12093TH057Core sequence. Contact residues are defined by a $5 \AA$ cutoff and marked above the sequence with (+) for side chain and (-) for main chain to indicate the type of contact. Contact types are colored as following: hydrophilic (green), hydrophobic (blue) and both (black). Buried surface residues are as determined by PISA and are shaded green.

formed by both antibodies are highly similar with root mean square deviations (RMSD) between main chain atoms of the variable domains of the Fab and the variable domains of the Fabgp120 core interface of 0.72 and $1.03 \AA^{2}$, respectively (Figure 5). Altogether the structural analysis confirms the close similarity between RhDH677.3 and DH677.3 with regard to their recognition of gp120, although sequence differences within framework regions do modulate the binding interface even when they only make minor contributions, either directly like $\mathrm{Ala}^{1}$ in the macaque light chain or indirectly like $\mathrm{Thr}^{30}$ in the macaque heavy chain.

The second rhesusized mAb included for structural characterization was DH827, an antibody from the RV144 vaccine trial (30). In contrast to DH677.3 which is specific for a discontinuous, conformational epitope, DH827 recognizes a linear epitope within the V2 loop region. Interestingly, V2 loop specific antibodies fall into four main categories depending upon the V2 loop conformation and epitope region (66). V2qt and $\mathrm{V} 2 \mathrm{q}$ antibodies bind the V2 loop in the quaternary trimeric form of the envelope structure (V2qt) such as PGT145 or (V2q) such as PG9 and PG16. V2i antibodies, e.g. 830A, directly overlap the $\alpha_{4} \beta_{7}$ integrin binding site on the V2 loop, and V2p antibodies bind the V2 loop in peptide-like conformation that only partially overlaps the integrin binding site, e.g. RV144 mAbs CH58, CH59, and DH827 (67-69). A sieve analysis of breakthrough HIV-1 infections in RV144 identified Lys ${ }^{169}$ as a site of antibody induced pressure on the virus (7). V2p antibodies from RV144 vaccinees (including DH827) often contain a Glu-Asp motif in 


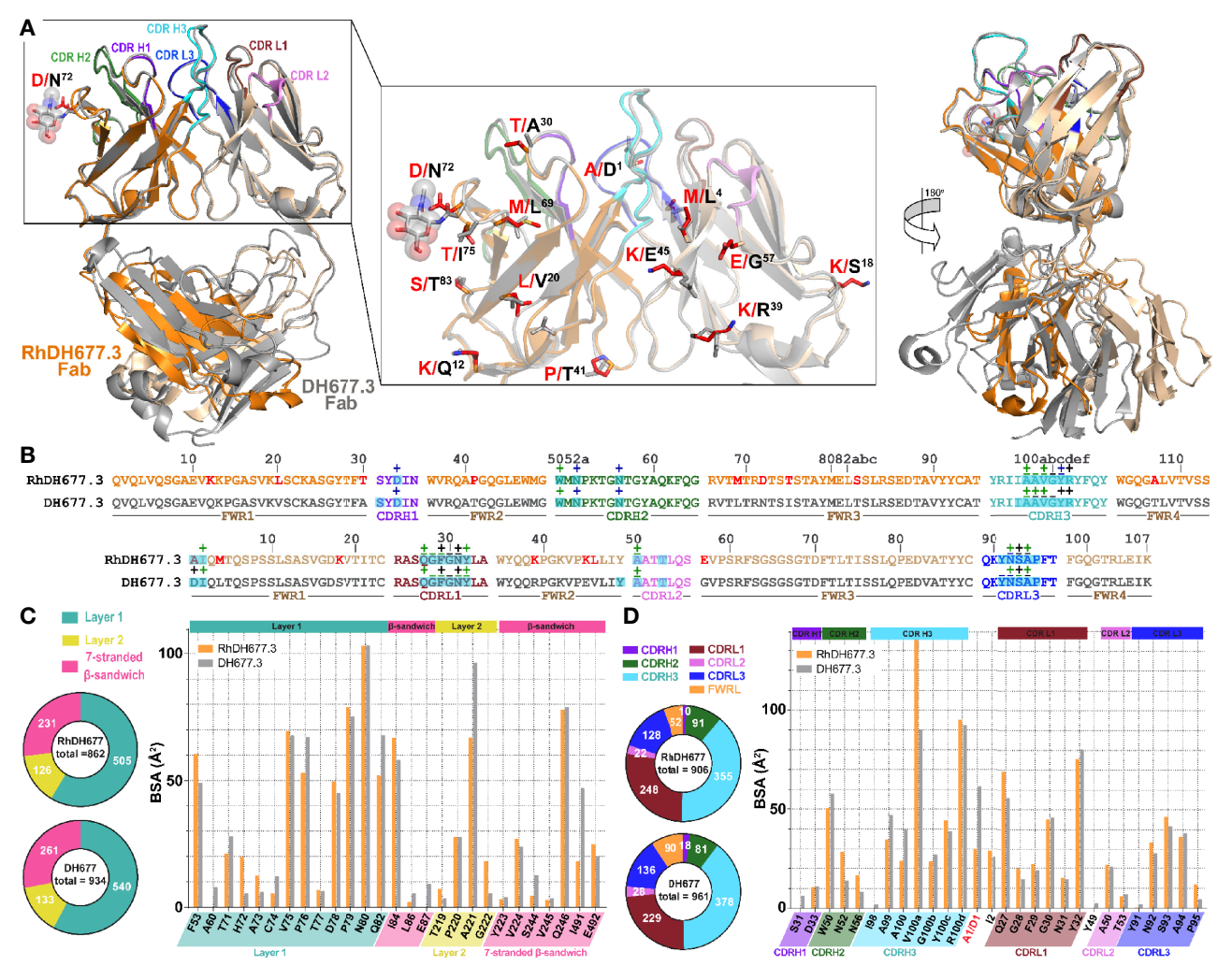

FIGURE 4 | Structural comparison of RhDH677.3 and DH677.3 Fab antigen complexes. (A) The RhDH677.3 Fab and its CDRs are colored as indicated in Figure 3 and the DH677.3 Fab is colored in gray. The complexes are superimposed based on the variable domains of light and heavy chains. Residues that differ between the two Fab are shown in stick and highlighted in red for RhDH677.3 Fab and in black for DH677.3 Fab (middle panel). A $180^{\circ}$ view reveals the structural difference of the constant domains in RhDh677.3 and DH677.3 Fabs (right panel) (B) Contact residues of RhDH677.3 and DH677.3 Fabs with gp120 are mapped onto the Fab sequences and colored as described for panel (A) Contact residues are defined by a $5 \AA$ cutoff and marked above the sequence with (+) for side chain and (-) for main chain to indicate the type of contact. Contact types are colored as following: hydrophilic (green), hydrophobic (blue) and both (black). Residues that differ between RhDH677.3 and DH677.3 are highlighted in red. Buried surface residues are determined by PISA and are shaded green. (C) Pie charts showing the buried surface binding (BSA) contributions of gp120 to binding and are colored as in Figure 3 . The BSA contributions to binding of gp120 residues are shown as calculated by PISA. BSA contributions for gp120 contact residues to RhDH677.3/DH677.3 binding are shown in orange and gray, respectively. (D) Pie charts showing the buried surface binding (BSA) contributions to gp120 binding for RhDH677.3/DH677.3 Fabs and are colored as in panel (A) The BSA contributions to binding for RhDH677.3 CDR residues are colored in orange and BSA contributions to binding for DH677.3 CDR residues are shown in gray.

their CDR L2 and depend on Lys ${ }^{169}$ in binding the V2 loop (70). DH827 differs from many other V2p Abs in that it is less dependent upon Lys ${ }^{169}$.

In order to confirm that the rhesusized RhDH827 mAb maintains the V $2 \mathrm{p}$ specificity of its parent $\mathrm{mAb}$, we crystallized RhDH827 in complex with a clade A/E 93TH057gp120 V2 sequence peptide (Table 1, Figure 6). The crystals belonged to space group C2, diffracted to 2.0 A resolution, and contained one RhDH827 Fab heavy and light chain bound to one V2 peptide in the asymmetric unit. RhDH827 binds the V2 peptide in a more helical conformation than many of the other RV144 Abs, e.g. $\mathrm{CH} 58$ and $\mathrm{CH} 59$, which allows it to make hydrophobic contacts with $\mathrm{Val}^{172}, \mathrm{Leu}^{175}, \mathrm{Phe}^{176}$, and Leu ${ }^{179}$. A discontinuation of the helix at the C-terminus allows it to extend its contacts to $\mathrm{Ile}^{181}$, $\mathrm{Val}^{182}$, and Pro ${ }^{183}$ (Figures 6B, C). Sixty-seven (67)\% of the total $852 \AA^{2}$ peptide BSA comes from these hydrophobic residues as opposed to $21.4 \%$ from Lys $^{168}$ and Lys $^{169}$ (Figures 6D, E).
Outward facing residues of the helix contribute little if anything to the peptide BSA, i.e. $\mathrm{Gln}^{170}$, $\mathrm{Lys}^{171}$, Ala ${ }^{174}$, $\mathrm{Tyr}^{177}$, and Lys ${ }^{179}$. Likewise, RhDH827 is also less dependent upon Lys $^{169}$. It focuses instead upon Lys ${ }^{168}$ and downstream hydrophobic residues in the V2 sequence; Lys ${ }^{169}$ accounts for $8.7 \%$ of the total peptide BSA while Lys ${ }^{168}$ accounts for $12.7 \%$ (Figures 6C-E). RhDH827 binds the V2 peptide mainly with CDRs H2, H3, L1 and L3. Glu ${ }^{50}$ and Asp ${ }^{51}$ of the Glu-Asp motif in CDR L2 make salt bridges with Lys ${ }^{169}$ and Lys ${ }^{168}$ of the peptide respectively, but account for almost all of CDR L2's contribution to binding (Figure 6F). CDRs L1 and L3 provide much of the remaining contact surface for the $\mathrm{N}$-terminus of the peptide, while CDRs $\mathrm{H} 2$ and $\mathrm{H} 3$ primarily interact with the $\mathrm{C}$ terminus. The total light chain BSA contribution to the interface is $293 \AA^{2}, 124 \AA^{2}$ from CDR L1, $37 \AA^{2}$ from CDR L2, and $130 \AA^{2}$ from CDR L3, and the total heavy chain BSA contribution 492 $\AA^{2}, 51 \AA^{2}$ from CDR H1, $184 \AA^{2}$ from CDR H2, and $257 \AA^{2}$ from 


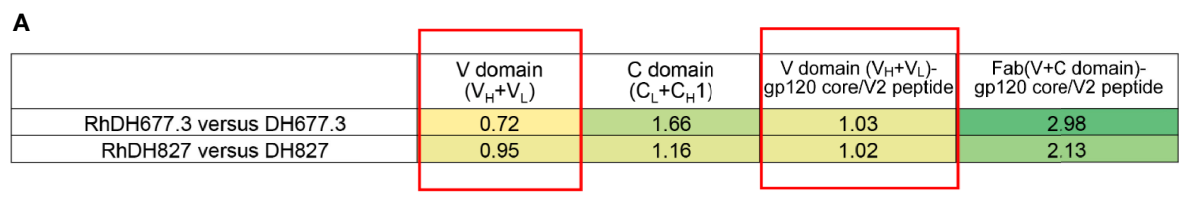

B

$C$ domain $\left(C_{L}+C_{H} 1\right)$, Kappa light chain

\begin{tabular}{|c|c|c|c|c|c|c|}
\hline & RhDH677.3 & 6 U6M & 6 U6O & 6 VOR & 6 VOS & 6 VSR \\
\hline RhDH677.3 & & 2.84 & 2.91 & 1.80 & 1.86 & 2.00 \\
\hline 6U6M & 2.84 & & 0.79 & 2.77 & 2.79 & 2.87 \\
\hline 6U6O & 2.91 & 0.79 & & 2.77 & 2.81 & 2.83 \\
\hline 6VOR & 1.80 & 2.77 & 2.77 & & 0.54 & 0.74 \\
\hline 6VOS & 1.86 & 2.79 & 2.81 & 0.54 & & 1.04 \\
\hline 6VSR & 2.00 & 2.87 & 2.83 & 0.74 & 1.04 & \\
\hline
\end{tabular}

C domain $\left(C_{L}+C_{H} 1\right)$, Lambda light chain

\begin{tabular}{|c|c|c|c|c|c|c|c|c|}
\hline & RhDH827 & 4RFE & $3 Q 6 G$ & $4 Q 2 Z$ & $5 T 4 Z$ & 5 UKN & 5 UKO & 5 UKP \\
\hline RhDH827 & & 0.89 & 0.72 & 0.96 & 0.90 & 0.96 & 0.98 & 0.62 \\
\hline 4RFE & 0.89 & & 0.97 & 0.98 & 0.89 & 1.19 & 1.21 & 0.97 \\
\hline 3Q6G & 0.72 & 0.97 & & 1.21 & 0.84 & 1.27 & 1.39 & 0.59 \\
\hline 4Q2Z & 0.96 & 0.98 & 1.21 & & 1.07 & 1.05 & 1.15 & 0.86 \\
\hline $5 \mathrm{~T} 4 Z$ & 0.90 & 0.89 & 0.84 & 1.07 & & 1.18 & 1.26 & 0.90 \\
\hline $5 \mathrm{UKN}$ & 0.96 & 1.19 & 1.27 & 1.05 & 1.18 & & 0.33 & 0.67 \\
\hline 5UKO & 0.98 & 1.21 & 1.39 & 1.15 & 1.26 & 0.33 & & 0.73 \\
\hline 5UKP & 0.62 & 0.97 & 0.59 & 0.86 & 0.90 & 0.67 & 0.73 & \\
\hline
\end{tabular}

FIGURE 5 | Comparison of overall structures of Rhesusized mAb variants to human and RM counterparts. (A) RMSD values for main chain atoms for pairwise comparisons of Fab V or C domains and Fab V or Fab-gp120 core complex between rhesusized and human variants. (B) RMSD values for main chain atoms for pairwise comparisons of Fab C domains of RhDH677.3 and RhDH827 to RM mAb Fabs available in the PDB with kappa and lambda light chains, respectively.

CDR H3 (Table S2). Aside from the two salt bridges from CDR L2 $\left(\mathrm{Glu}^{50}\right.$ and $\mathrm{Asp}^{51}$ to Lys ${ }^{169}$ and Lys ${ }^{168}$ respectively) and three hydrogen bonds from the heavy chain (one from CDR H3 Ser ${ }^{100}$ to $\mathrm{His}^{173}$ and two from CDR H2 tyrosine residues to the main chain carbonyls of $\mathrm{Leu}^{179}$ and $\mathrm{Il}^{181}$ ) most of the interface is hydrophobic in nature which may help it tolerate mutations that disrupt the salt bridges to Lys ${ }^{168}$ or Lys ${ }^{169}$ and changes to Ile ${ }^{181}$, the hydrophobic residue with the single largest contribution to the BSA; changes in Lys ${ }^{169}$ and Ile ${ }^{181}$ were identified in RV144 breakthrough viruses implicating this region in the protective effect of the vaccine (7).

RhDH827 was crystalized with the same V2 peptide as used previously for its human counterpart DH827 (30) however, the complex structure of $\mathrm{RhDH} 827$ was solved at higher resolution (2.0 versus $2.9 \AA$ for DH827). In addition, there is a one amino acid insertion in the light chain CDR L3 at position 95A of $\mathrm{RhDH} 827$ that is absent in DH827 due to a difference in sequence between the clone of DH827 used to generate RhDH827 (30). These differences slightly complicate the direct comparison of the two structures. Although the RMSD value for the comparison of the main chain atoms of the antibody variable domains and the bound peptide is very low, $1 \AA$ (Figure 5A), there are some differences in specific contacts at the antibodypeptide interface. For example, in the RhDH827-V2 complex, Lys $^{168}$ and Lys ${ }^{169}$ of peptide account for approximately $18 \%$ of the total peptide BSA with $8.9 \AA^{2}$ and $9.1 \AA^{2}$ contributed for Lys $^{168}$ and Lys ${ }^{169}$, respectively. Furthermore, in the RhDH827 complex, the $\mathrm{N}$-terminus of the peptide fold into an amphipathic helical conformation with hydrophobic residues from that region $\mathrm{Val}^{172}$, Leu ${ }^{175}, \mathrm{Phe}^{176}$, and Leu ${ }^{179}$ together with those from the C-terminus after a break in the helix e.g. Ile ${ }^{181}, \mathrm{Val}^{182}$, and Pro ${ }^{183}$, making up approximately $65 \%$ of the peptide BSA. This is comparable to the $67 \%$ seen for the corresponding residues in the DH827 complex, but the total peptide BSA is significantly lower for the human antibody, $817 \AA^{2}$ versus $852 \AA^{2}$. The lower resolution of the human complex could potentially explain this difference; density for the peptide is weaker at both the $\mathrm{N}$ and $\mathrm{C}$ termini in the human structure which makes the side chain positions for these residues less certain.

Interestingly, contributions from the heavy and light chain CDRs are roughly comparable between the two structures with the exception of one major difference in CDR L3. RhDH827 has an extra histidine, His ${ }^{95 \mathrm{~A}}$, relative to the human $\mathrm{DH} 827$, due to a difference in the DH827 clone used to make RhDH827 (Figure 6C and Figure S2). This changes the conformation of the CDR L3 loop. As a consequence, CDR L3 $\mathrm{Ile}^{94}$ makes the same contacts to the peptide in the human complex that CDR L3 $\mathrm{Thr}^{94}$ makes to the peptide in the rhesusized complex. His ${ }^{95 \mathrm{~A}}$ itself adds little to the interface. The slightly shorter CDR L3 in the human structure also changes the conformation of the C-t2erminus of the peptide, mainly in the area near the end of the peptide helix. This conformational difference may explain the slightly higher BSAs for CDR H3 Pro ${ }^{99}$ and CDR L1 Tyr ${ }^{32}$ in the human structure. Outside of these regions the structures are largely identical with similar BSA values for both the heavy and light chain residues as can be seen in the bar chart of BSA by residue (Figure 6F). 

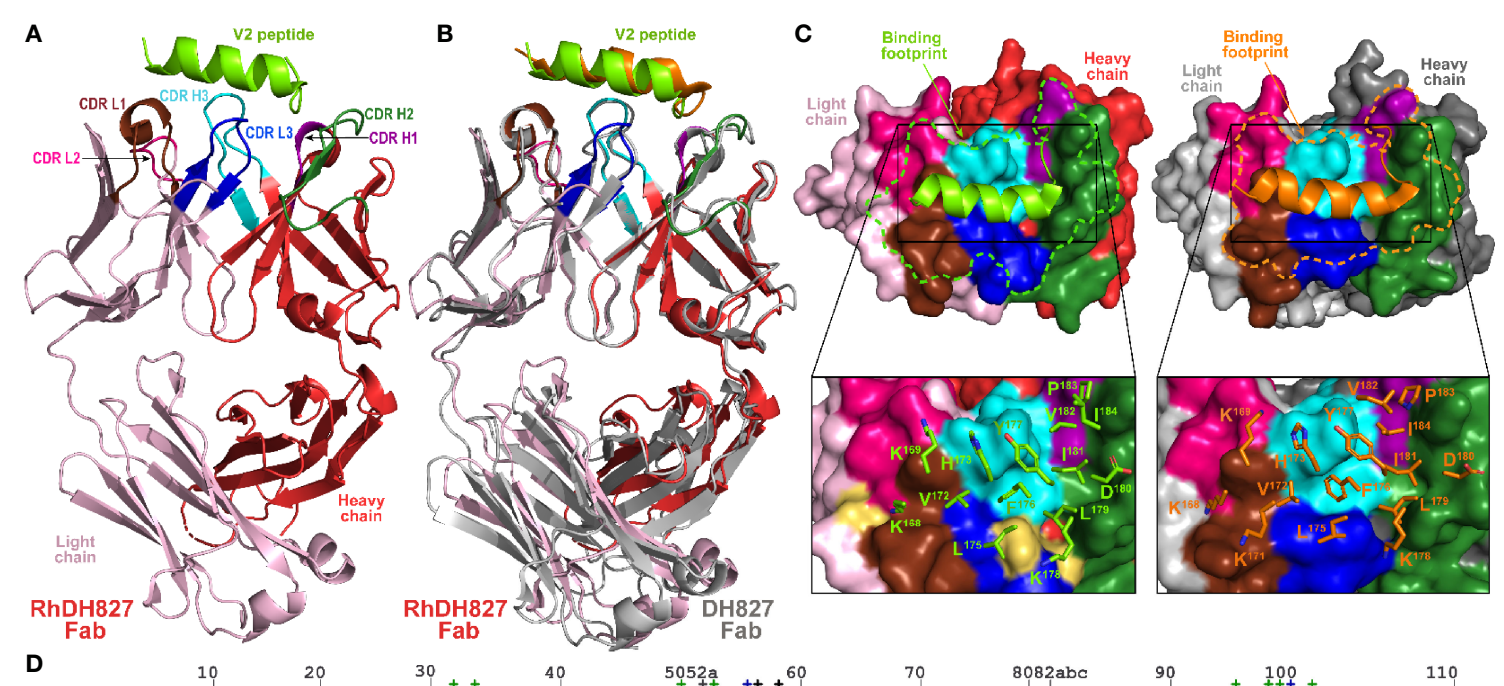

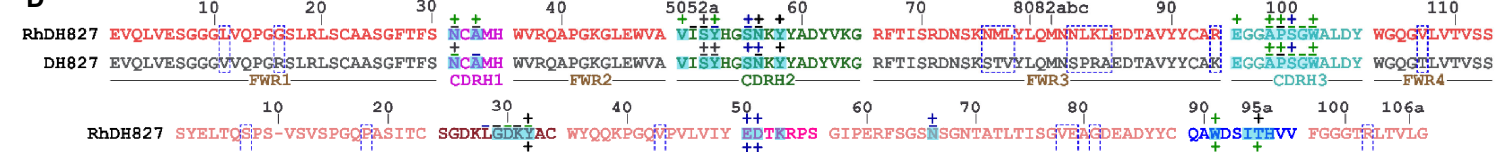

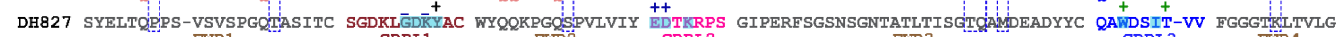

E
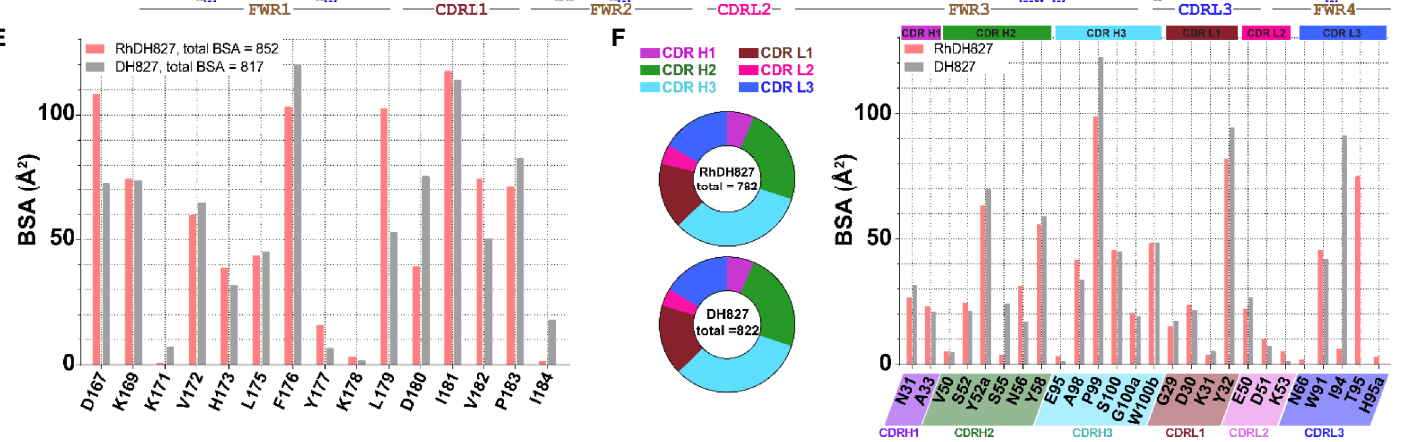

FIGURE 6 | Crystal structure ofRhDH827 Fab-V2 peptide complex. (A) The overall structure of the complex is shown as a ribbon diagram. The V2 peptide is green and the light chain (LC) and heavy chain ( $\mathrm{HC})$ of RhDH827 Fab are colored in light pink and red, respectively. The CDRs of RhDH827 Fab are colored as following colors: CDR L1 (brown), CDR L2 (pink), CDR L3 (blue), CDR H1 (purple), CDR H2 (dark green), and CDR H3 (cyan). (B) Structural comparison of RhDH827 Fab-V2 peptide and DH827 Fab-V2 peptide complexes. The RhDH827 Fab-V2 peptide complex is colored as indicated in panel A and the DH677.3 Fab-V2 peptide complex is colored in gray with V2 peptide colored in orange. The complexes are superimposed based on the variable heavy $\left(\mathrm{V}_{H}\right)$ domain. (C) RhDH827 andDH827 Fabs are shown as a molecular surface and the CDRs of both Fabs surface are colored as in panel (A) The light chain (LC) and heavy chain (HC) of DH827 Fab are colored in light and dark gray, respectively. Binding footprints for V2 peptide on RhDH827 and DH827 Fabs are outlined in green and orange, respectively (top panel). Residues contributing to the binding are shown as sticks (bottom panel). Extra binding residues on RhDH827 are colored in yellow. (D) Contact residues of RhDH827 and DH827 Fabs with V2 peptide are mapped onto the Fab sequences and colored as described for panel (A) Contact residues are defined by a $5 \AA$ cutoff and marked above the sequence with (+) for side chain and (-) for main chain to indicate the type of contact. Contact types are colored as following: hydrophilic (green), hydrophobic (blue) and both (black). Residues that differ between RhDH827 and DH827 are highlighted in blue dashed-line box. Buried surface residues are determined by PISA and are shaded green. (E) The buried surface area (BSA) contributions of V2 peptide to binding of RhDH827/DH827 Fabs are shown in red and gray, respectively. The BSA contributions to binding of V2 residues as calculated by PISA. (F) Pie charts showing the BSA of RhDH827/DH827 Fabs buried at the complex interface and are colored as in panel (A) The BSA contributions to binding for RhDH827 CDR residues are colored in red and BSA contributions to binding for DH677.3 CDR residues are shown in gray.

\section{Constant (C) Regions of Rhesusized mAb Variants Show Close Structural Similarity to C Domains of RM IgG1}

Analysis of the structures of Fab-antigen complexes of rhesusized and human IgG pairs confirm close similarity of their $\mathrm{V}$ domain structures and good preservation of the contacts at the antigenFab interface. While in the rhesusized IgG1 variants the V domains are of mixed sequence, assembled from the closest
RM germline framework mAb sequence and CDRs engrafted from human counterpart, the $C$ domains $\left(C_{L}+C_{H} 1\right)$ are unchanged and formed from fully RM IgG1 sequences (Figure 1). Of note RhDH677.3 and RhDH827 represent kappa and lambda light chains, respectively. In order to check if sequence changes in the $\mathrm{V}$ domains contribute to changes in overall architecture of the rhesusized variant $\mathrm{C}$ domains we compared the structures of the $\mathrm{C}$ domains of RhDH677.3 and 
RhDH827 to C domain structures from RM IgG1 Fabs available in Protein Data Bank (Figure 5B). We used entries from PDB of antibodies of different specificities (including antibodies unrelated to HIV-1) but matched RhDH677.3 with antibodies with kappa light chains and RhDH827 with antibodies with lambda light chains. Overall the RMSD values for the C domains of RhDH677.3 as compared to the other kappa light chain containing antibodies fell within a range of 1.8-2.91 $\AA$ which is slightly higher than the highest RMSD value for kappa light chain antibody comparisons in the absence of RhDH677.3 (RMSD range of 0.54-2.87 $\AA$ ). In contrast, the RMSDs for the $\mathrm{C}$ domains of RhDH827 as compared to the other lambda light chain containing antibodies fell within a range of 0.62-0.98 which is lower than the RMSD range for all other lambda antibodies in the absence of RhDH827 (0.33-1.39 $\AA$ ). This indicates that there is a poorer agreement among the kappa light chain $\mathrm{C}$ domain structures in general and with RhDH677.3 in particular although this could be in part due to the lower resolution from the RhDH677.3 complex structure. The better agreement among the $\mathrm{C}$ domain structures with lambda light chains may be a reflection of the higher resolution of the RhDH827 structure but it could also be in part due to the fewer number of changes relative to the human sequence for the lambda light chain, 12, versus the kappa light chain, 17, since human lambda and kappa C domains were initially used as models for the generation of both structures.

\section{Rhesusized mAb Variants Mediate Antibody Fc Effector Functions (i.e. Recognition of SHIV-1 Infected Cells, ADCC, ADCP, ADNP, and Virion Capture) Comparable to Their Human Counterparts}

Structural and SPR analyses indicate that the rhesusized $\mathrm{mAb}$ variants preserve the antigen binding properties of their human counterparts, and SPR binding confirms that their binding affinities to the low affinity RM and human Fc $\gamma$ Rs are comparable to mAbs of $\mathrm{RM}$ origin. To see if these features translate into 'proper' functional activity, we assessed their binding to HIV-infected CEM.NKR.CCR5 cells and SHIVinfected A66 cells using the gating strategy demonstrated in Figure 7A. We observed similar percentages of HIV-infected cells bound by each pair of human and rhesusized mAb (\% Ab +p24/p27+) to each HIV-1 Infectious Molecular Clone (IMC) and SHIV tested here (Figure 7B). The percentage of infected cells bound by the combination of three mAbs, DH677.3 (C1C2), DH827 (V2) and 7B2 (gp41) was also similar between human and macaque. The human version of DH677.3 demonstrated a difference in binding to SHIV.CH505.375 H- and SHIV.1157QNE(Y173H)-infected cells as compared to its rhesus counterpart. A similar increase in binding was observed with the V2-targeting RhDH827 Ab as compared to its human version to SHIV.SF162.P3-infected cells. Overall, there was similar binding of rhesusized mAbs to HIV-infected cells as compared to their human counterparts.

The ADCC activity of the rhesusized variants to their human counterparts was also compared using HIV-infected
CEM.NKR.CCR5 cells as targets in a luciferase-based ADCC assay (49). Peripheral blood mononuclear cells (PBMCs) isolated from an HIV-1-seronegative individual were used as effector cells and subtype B HIV-1 SF162-, subtype C HIV-1 CH505- or 1086infected cells were used as targets in the presence of serial dilutions of mAbs. We observed similar area under the curve (AUC) values for human and rhesus mAb pairs against the three IMCs tested here (Figure 7C). The analysis of ADCC activity for mAbs in the ADCC-GTL assay (51) also revealed similar magnitudes in AUC values for each individual $\mathrm{mAb}$ pair and for macaque and human mAb combinations (Figure S5).

The capacity of the C1-C2 and V2 specific rhesusized variants to mediate phagocytosis by monocytes (ADCP) and neutrophils (ADNP) was assessed using the THP-1 and HL-60 cell lines with SHIV 1157(QNE)Y173H gp120 protein coated microspheres, respectively (Figure 8A). Overall, the rhesusized Abs had similar levels of phagocytosis to their human counterparts. The V2 Abs had modestly higher phagocytosis scores compared to the $\mathrm{C} 1 \mathrm{C} 2$ specific antibodies, likely due to improved epitope exposure on Env protein. To assess recognition of virus particles as one of the first steps in antibody effector function, we also assessed the capacity of all 3 antibody specificities to bind infectious SHIV 1157(QNE)Y173H virions (Figure 8B). As expected, the C1C2 antibody specificities did not bind and capture virus. However, the V1V2 and gp41 specific antibodies did capture infectious virions.

Taken together these data indicate that rhesusized $\mathrm{mAb}$ binding and ADCC to in vitro infected cells are comparable antibody Fc effector functions for human mAb counterparts as well as anti-HIV-1 antibodies of human or rhesus origin.

\section{DISCUSSION}

The number of antibodies and antibody-based therapeutics used clinically continues to grow $(71,72)$. Since many of these products are derived from antibodies from a nonhuman origin they need to be adapted to the human immune system, or 'humanized', before they can be used clinically. Simple grafting of an antibody's complementary determining regions (CDRs) to a human antibody backbone sequence often leads to reduced antigen affinity either by omission of paratope residues outside of the CDRs or by subtle structural changes due to differences in the sequence of framework residues. Conversely, grafting of the entire heavy and light chain variable domain, $\mathrm{V}_{\mathrm{H}}$ and $\mathrm{V}_{\mathrm{L}}$, onto constant heavy and light chain backbones to make a chimera, while maintaining paratope structure introduces a greater number changes and potentially increases immunogenicity. This has typically made humanization of antibodies a multistep process in which the initial incarnation of a humanized antibody is subsequently modified to increase its affinity for antigen in order to match that of the parent $\mathrm{mAb}$. The sequencing of the human genome has aided this process by making it possible to identify the closest germline sequence to minimize the number of needed residue changes and potentially decrease immunogenicity. 

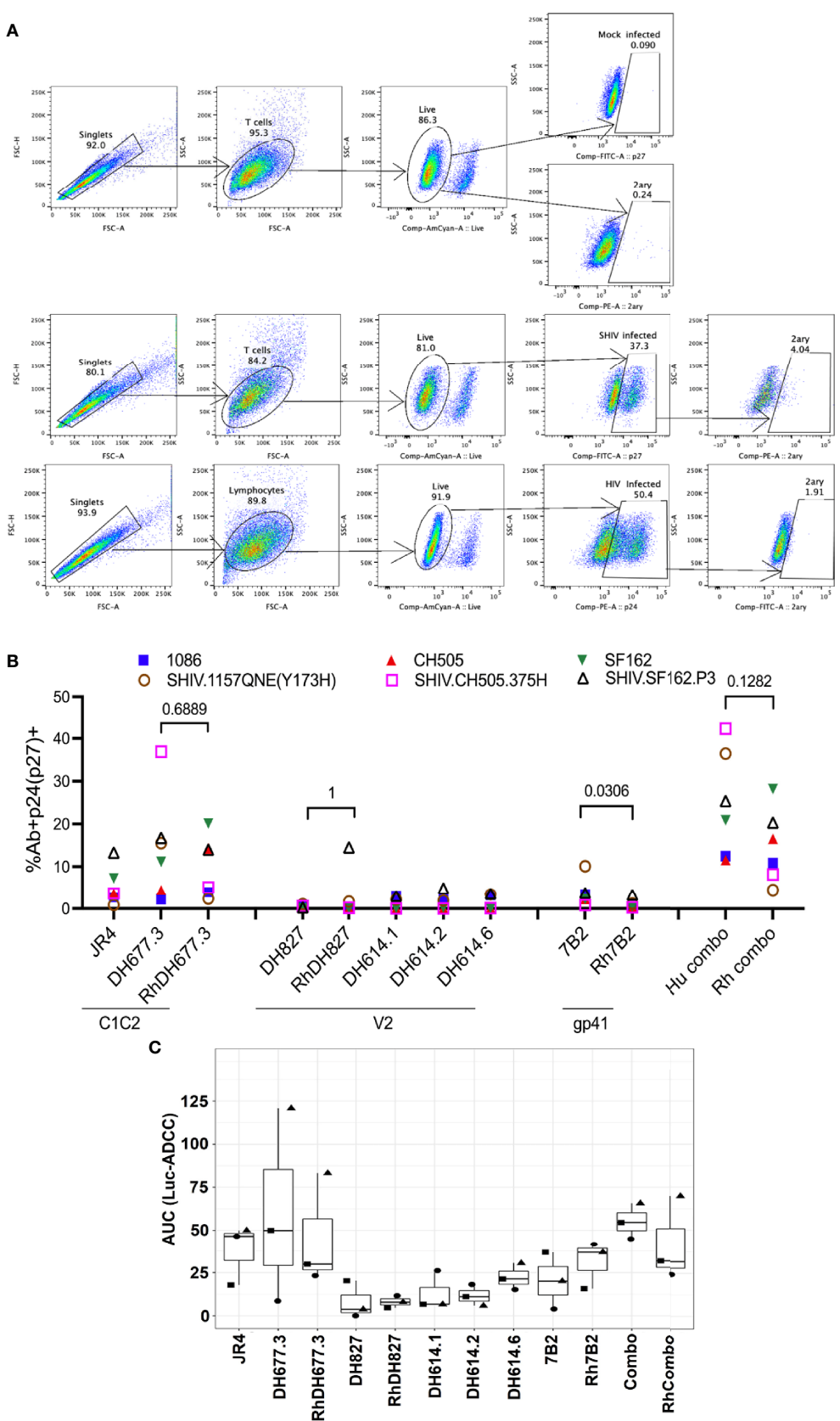

FIGURE 7 | ADCC activities of rhesusized mAb variants. (A) The gating strategy for the binding of mAbs to HIV.IMC-infected CEM.NKR cells and SHIV-infected A66 cells. The binding of mAbs to mock-infected cells (top), SHIV-infected A66 cells (middle) and HIV-infected CEM.NKR cells and (bottom). Cells were first gated for singlets (FSC-H vs. FSC-A) and T cells (SSC-A vs. FSC-A). The T cells were further analyzed for their uptake of the Live/Dead Aqua stain to determine live versus dead cells. Live cells were analyzed for the intracellular expression of p24 or p27. Each well was stained either with anti-p24 (CEM.NKR cells that were infected with HIV) or anti-p27 antibody (A66 cells infected with SHIV). Infected cells, p24+ (infected with HIV.IMCs) or p27+ (infected with SHIVs), were analyzed for binding of the tested mAb by staining with a secondary mAb (2ary). The far-right panel indicate $2 a r y ~ A b$ only (these are the well that lack primary Ab of interest) which shows that in presence of secondary antibody alone we did not detect any binding to either mock or infected cells. Mock-infected cells were used to properly set the gate for the infected cell population and the 2ary mAb. FSC, forward scatter; SSC, side scatter. (B) The percentage of infected cells bound by the tested mAb. The antibodies listed on the $x$-axis are grouped by the epitope specificity: C1C2 (RM JR4, DH677.3), V2 (DH827, RM DH614.1, RM DH614.2, RM DH614.6), gp41 immunodominant (gp41), and the combination (DH677.3, DH827, 7B2). Each color represents a different HIV-1 Infectious Molecular Clone (IMC) or SHIV. Each Ab/virus combination was tested once using a single well. (C) ADCC activities are shown as area under the curve (AUC) for each mAb calculated from dilution curves (starting concentration $50 \mu \mathrm{g} / \mathrm{mL}$ with $1: 5$ serial dilutions) against HIV.IMC-infected cells determined by a Renilla Luciferase-based ADCC assay (Luc-ADCC) with PBMCs from an HIV-1-seronegative individual as effectors at an E:T ratio of 30:1. Each symbol represents a different IMC. Each experiment in panel $\mathrm{C}$ was performed once with two biological replicates. Wilcoxon rank sum test was used to assess statistical significance; $p$-values less than 0.05 were considered significant. 

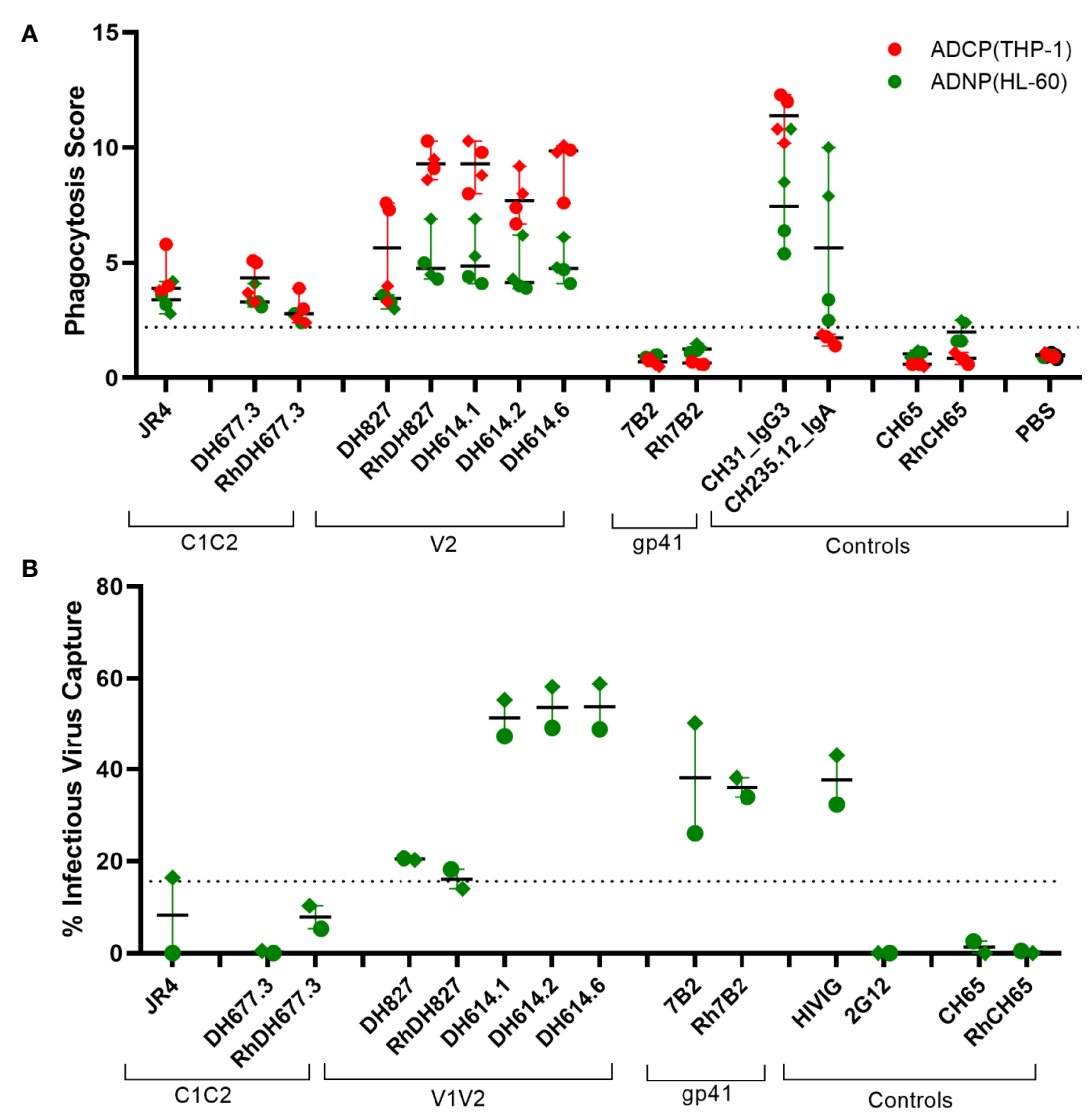

FIGURE 8 | Virion binding and phagocytic activities of Rhesusized mAb (A) Antibody-dependent phagocytosis of monocytes using monocytic THP1 cell line and neutrophils using HL60 cell line with SHIV 1157(QNE)Y173H gp120-coated beads. (B) Binding of antibody variants to infectious SHIV1157(QNE)Y173H. Dotted lines represent positivity cutoffs of $15.6 \%$ and 2.2 for virus capture and ADCP/ADNP, respectively. The data represent an average of two independent experiments with two replicates for each experiment for ADCP/ADNP and one replicate for virion binding. Rhesus macaque antibody versions are marked with Rh. Positive controls (CH31 lgG3, CH235.12 lgA) and negative controls (7B2, Rh7B2, Ch65, RhCH65 and PBS) are shown.

The close phylogenetic relationship between humans and nonhuman primates (NHPs), including Rhesus macaque (RM), Macaca mulatta, makes them an important animal model in the testing of new vaccines, antibodies or antibody based therapeutics. For human antibodies to be tested in RM this requires the reverse of humanization, i.e. rhesusization. The latter is essential to enable proper interaction with host immune system. Ideally this is done with the fewest number of sequence changes both to preserve the paratope structure of the parent $\mathrm{mAb}$ and to minimize immunogenicity. Here we have applied the rhesusization process to three human anti-HIV-1 antibodies recognizing Env which impact the virus predominantly by a Fc-effector mechanism (DH677.3, DH827, and 7B2) to facilitate their use in future NHP challenge studies.

We were able to obtain crystal structures of antigen complexes for two of our rhesusized variants in conditions similar to those used to obtain the structures of their human counterparts. This allowed us to perform a detailed analysis of the complex interface and to detect any changes introduced in the rhresusization process. Some slight differences were seen in the RhDH677.3 complex in contacts made by the Fab outside of the CDRs. Framework residues from the human $\mathrm{mAb}$ contributed slightly more to the interface than the corresponding residues from the rhesusized version. Interestingly, these differences could largely be attributed to positions that differed between the human and macaque germline sequences and are reflected in the total interface BSA, $1800 \AA^{2}$ for RhDH677.3 and $1984 \AA^{2}$ for DH677.3, and in the approximately 8 -fold reduction in affinity for RhDH677.3 to antigen. Thus, for antibodies that involve framework residues in antigen engagement, rhesusization within framework areas should to be done carefully to avoid losses that can potentially lead to a decrease of affinity to antigen. Similar conclusions could be drawn from the comparison of the human and macaque versions of DH827 although a one residue difference in sequence in the light chain and different resolutions for the two structures made the comparison more difficult.

Importantly, the Fc-functionality of the rhesusized mAbs were fully preserved. SPR results confirmed that the rhesusized mAbs had affinities to both macaque and human FcyRs similar to $\mathrm{mAbs}$ originally isolated from RM. Rhesusized mAbs also bound 
to HIV-1 infected cells at levels comparable to those of their human counterpart. They also displayed ADCC, ADCP and ADNP activities in the same range as macaque mAbs of similar specificity.

In conclusion, reducing immunogenicity potentially comes at the cost of reduced affinity to antigen. Even highly somatically mutated species matched antibodies can elicit immune reactions that remove them from circulation. This has been the case in macaques with the introduction of anti-SIV mAbs (73) and in humans with the introduction of broadly neutralizing antibodies against HIV-1, PG9 in clinicaltrials.gov NCT01937455 (74) and VRC07 in VRC 603, clinicaltrials.gov NCT03374202 (75). Rhesusization can potentially minimize the impact of such offtarget reactions and extend their half-life in sera when they are evaluated in NHP models (33), but anti-idiotype immune responses are still possible (76). Rhesusization also places the antibody specificity within the context of the host immune response affording a more direct comparison to vaccine elicited antibodies of similar specificity. This may enable use of the RM model to more accurately test antibody correlates of protection from HIV-1 infection identified in human vaccine trials and more generally antibodies and antibody based therapeutics that utilize Fc mediated effector functions as part of their mechanism of action.

\section{DATA AVAILABILITY STATEMENT}

The datasets generated and/or analyzed during the current study are available in the Protein Data Bank (PDB) http://www.rcsb. org under admission codes: 6OZ2 and 6OZ4.

\section{AUTHOR CONTRIBUTIONS}

WT, DN, GT, GF, and MP designed, performed research, and analyzed the data, MT, SJ, and GF designed, performed, and analyzed cell binding and ADCC data. AC, YC, and MA designed, performed, and analyzed SPR binding data. KW helped with rhesus germline gene inference. GT, KS, and JP

\section{REFERENCES}

1. Rerks-Ngarm S, Pitisuttithum P, Nitayaphan S, Kaewkungwal J, Chiu J, Paris $\mathrm{R}$, et al. Vaccination With ALVAC and AIDSVAX to Prevent HIV-1 Infection in Thailand. N Engl J Med (2009) 361(23):2209-20. doi: 10.1056/ NEJMoa0908492

2. Bonsignori M, Pollara J, Moody MA, Alpert MD, Chen X, Hwang KK, et al. Antibody-Dependent Cellular Cytotoxicity-Mediating Antibodies From an HIV-1 Vaccine Efficacy Trial Target Multiple Epitopes and Preferentially Use the VH1 Gene Family. J Virol (2012) 86(21):11521-32. doi: 10.1128/ JVI.01023-12

3. Haynes BF, Gilbert PB, McElrath MJ, Zolla-Pazner S, Tomaras GD, Alam SM, et al. Immune-Correlates Analysis of an HIV-1 Vaccine Efficacy Trial. N Engl J Med (2012) 366(14):1275-86. doi: 10.1056/NEJMoa1113425

4. Tomaras GD, Ferrari G, Shen X, Alam SM, Liao HX, Pollara J, et al. VaccineInduced Plasma IgA Specific for the C1 Region of the HIV-1 Envelope Blocks designed and produced RM IgG variants. DG and GT designed and analyzed phagocytosis experiments. AD, GL, DE, MM, $\mathrm{VB}$, and $\mathrm{SM}$ helped design the $\mathrm{mAb}$ selections and experiments. JT and AP provided the SHIV QNE and helped with experimental design. WT, DN, and MP wrote the manuscript and all authors provided comments or revisions. All authors contributed to the article and approved the submitted version.

\section{FUNDING}

Funding for this study was provided by the National Institute of Health grants: P01 AI120756 to GT, R01 AI116274 to MP, R01 AI129769 to MP, with support from the Duke Center for AIDS Research P30 AI064518. The funders had no role in study design, data collection and analysis, decision to publish, or preparation of the manuscript and the contents of this publication are solely the responsibility of the authors.

\section{ACKNOWLEDGMENTS}

We thank Sheetal Sawant, Duke University for statistical advice. Use of the Stanford Synchrotron Radiation Lightsource, SLAC National Accelerator Laboratory, is supported by the U.S. Department of Energy, Office of Science, Office of Basic Energy Sciences under Contract No. DE-AC02-76SF00515. The SSRL Structural Molecular Biology Program is supported by the DOE Office of Biological and Environmental Research, and by the National Institutes of Health, National Institute of General Medical Sciences.

\section{SUPPLEMENTARY MATERIAL}

The Supplementary Material for this article can be found online at: https://www.frontiersin.org/articles/10.3389/fimmu.2021.787603/ full\#supplementary-material

Binding and Effector Function of IgG. Proc Natl Acad Sci USA (2013) 110):9019-24. doi: 10.1073/pnas.1301456110

5. Li SS, Gilbert PB, Tomaras GD, Kijak G, Ferrari G, Thomas R, et al. FCGR2C Polymorphisms Associate With HIV-1 Vaccine Protection in RV144 Trial. J Clin Invest (2014) 124(9):3879-90. doi: 10.1172/JCI75539

6. Karasavvas N, Billings E, Rao M, Williams C, Zolla-Pazner S, Bailer RT, et al. The Thai Phase III HIV Type 1 Vaccine Trial (RV144) Regimen Induces Antibodies That Target Conserved Regions Within the V2 Loop of Gp120. AIDS Res Hum Retroviruses (2012) 28(11):1444-57. doi: 10.1089/ aid.2012.0103

7. Rolland M, Edlefsen PT, Larsen BB, Tovanabutra S, Sanders-Buell E, Hertz T, et al. Increased HIV-1 Vaccine Efficacy Against Viruses With Genetic Signatures in Env V2. Nature (2012) 490(7420):417-20. doi: 10.1038/ nature11519

8. Gottardo R, Bailer RT, Korber BT, Gnanakaran S, Phillips J, Shen X, et al. Plasma IgG to Linear Epitopes in the V2 and V3 Regions of HIV-1 Gp120 
Correlate With a Reduced Risk of Infection in the RV144 Vaccine Efficacy Trial. PloS One (2013) 8(9):e75665. doi: 10.1371/journal.pone.0075665

9. Zolla-Pazner S, deCamp AC, Cardozo T, Karasavvas N, Gottardo R, Williams C, et al. Analysis of V2 Antibody Responses Induced in Vaccinees in the ALVAC/AIDSVAX HIV-1 Vaccine Efficacy Trial. PloS One (2013) 8(1): e53629. doi: 10.1371/journal.pone.0053629

10. Barouch DH, Liu J, Li H, Maxfield LF, Abbink P, Lynch DM, et al. Vaccine Protection Against Acquisition of Neutralization-Resistant SIV Challenges in Rhesus Monkeys. Nature (2012) 482(7383):89-93. doi: 10.1038/nature10766

11. Pegu P, Vaccari M, Gordon S, Keele BF, Doster M, Guan Y, et al. Antibodies With High Avidity to the Gp120 Envelope Protein in Protection From Simian Immunodeficiency Virus SIV(mac251) Acquisition in an Immunization Regimen That Mimics the RV-144 Thai Trial. J Virol (2013) 87(3):1708-19. doi: 10.1128/JVI.02544-12

12. Gordon SN, Doster MN, Kines RC, Keele BF, Brocca-Cofano E, Guan Y, et al. Antibody to the Gp120 V1/V2 Loops and CD4+ and CD8+ T Cell Responses in Protection From SIVmac251 Vaginal Acquisition and Persistent Viremia. J Immunol (2014) 193(12):6172-83. doi: 10.4049/jimmunol.1401504

13. Roederer M, Keele BF, Schmidt SD, Mason RD, Welles HC, Fischer W, et al. Immunological and Virological Mechanisms of Vaccine-Mediated Protection Against SIV and HIV. Nature (2014) 505(7484):502-8. doi: 10.1038/ nature 12893

14. Gordon SN, Liyanage NP, Doster MN, Vaccari M, Vargas-Inchaustegui DA, Pegu P, et al. Boosting of ALVAC-SIV Vaccine-Primed Macaques With the CD4-SIVgp120 Fusion Protein Elicits Antibodies to V2 Associated With a Decreased Risk of SIVmac251 Acquisition. J Immunol (2016) 197(7):2726-37. doi: $10.4049 /$ jimmunol.1600674

15. Vaccari M, Gordon SN, Fourati S, Schifanella L, Liyanage NP, Cameron M, et al. Adjuvant-Dependent Innate and Adaptive Immune Signatures of Risk of SIVmac251 Acquisition. Nat Med (2016) 22(7):762-70. doi: 10.1038/nm.4105

16. Malherbe DC, Mendy J, Vang L, Barnette PT, Reed J, Lakhashe SK, et al. Combination Adenovirus and Protein Vaccines Prevent Infection or Reduce Viral Burden After Heterologous Clade C Simian-Human Immunodeficiency Virus Mucosal Challenge. J Virol (2018) 92(2):e01092-17. doi: 10.1128/JVI.01092-17

17. Singh S, Ramirez-Salazar EG, Doueiri R, Valentin A, Rosati M, Hu X, et al. Control of Heterologous Simian Immunodeficiency Virus SIVsmE660 Infection by DNA and Protein Coimmunization Regimens Combined With Different Toll-Like-Receptor-4-Based Adjuvants in Macaques. J Virol (2018) 92(15):e00281-18. doi: 10.1128/JVI.00281-18

18. Felber BK, Lu Z, Hu X, Valentin A, Rosati M, Remmel CAL, et al. CoImmunization of DNA and Protein in the Same Anatomical Sites Induces Superior Protective Immune Responses Against SHIV Challenge. Cell Rep (2020) 31(6):107624. doi: 10.1016/j.celrep.2020.107624

19. Gray GE, Bekker LG, Laher F, Malahleha M, Allen M, Moodie Z, et al. Vaccine Efficacy of ALVAC-HIV and Bivalent Subtype C Gp120-MF59 in Adults. N Engl J Med (2021) 384(12):1089-100. doi: 10.1056/NEJMoa2031499

20. Shen X, Laher F, Moodie Z, McMillan AS, Spreng RL, Gilbert PB, et al. HIV-1 Vaccine Sequences Impact V1V2 Antibody Responses: A Comparison of Two Poxvirus Prime Gp120 Boost Vaccine Regimens. Sci Rep (2020) 10(1):2093. doi: 10.1038/s41598-020-57491-z

21. Neidich SD, Fong Y, Li SS, Geraghty DE, Williamson BD, Young WC, et al. Antibody Fc Effector Functions and IgG3 Associate With Decreased HIV-1 Risk. J Clin Invest (2019) 129(11):4838-49. doi: 10.1172/JCI126391

22. Boesch AW, Osei-Owusu NY, Crowley AR, Chu TH, Chan YN, Weiner JA, et al. Biophysical and Functional Characterization of Rhesus Macaque IgG Subclasses. Front Immunol (2016) 7:589. doi: 10.3389/fimmu.2016.00589

23. Chan YN, Boesch AW, Osei-Owusu NY, Emileh A, Crowley AR, Cocklin SL, et al. IgG Binding Characteristics of Rhesus Macaque FcgammaR. J Immunol (2016) 197(7):2936-47. doi: 10.4049/jimmunol.1502252

24. Tolbert WD, Subedi GP, Gohain N, Lewis GK, Patel KR, Barb AW, et al. From Rhesus Macaque to Human: Structural Evolutionary Pathways for Immunoglobulin G Subclasses. MAbs (2019) 11(4):709-24. doi: 10.1080/ 19420862.2019.1589852

25. Lejeune J, Brachet G, Watier H. Evolutionary Story of the Low/MediumAffinity IgG Fc Receptor Gene Cluster. Front Immunol (2019) 10:1297. doi: 10.3389/fimmu.2019.01297

26. Mascola JR, Lewis MG, Stiegler G, Harris D, VanCott TC, Hayes D, et al. Protection of Macaques Against Pathogenic Simian/Human
Immunodeficiency Virus 89.6PD by Passive Transfer of Neutralizing Antibodies. J Virol (1999) 73(5):4009-18. doi: 10.1128/JVI.73.5.40094018.199

27. Burton DR, Hessell AJ, Keele BF, Klasse PJ, Ketas TA, Moldt B, et al. Limited or No Protection by Weakly or Nonneutralizing Antibodies Against Vaginal SHIV Challenge of Macaques Compared With a Strongly Neutralizing Antibody. Proc Natl Acad Sci USA (2011) 108:11181-6. doi: 10.1073/ pnas. 1103012108

28. Shingai M, Donau OK, Plishka RJ, Buckler-White A, Mascola JR, Nabel GJ, et al. Passive Transfer of Modest Titers of Potent and Broadly Neutralizing Anti-HIV Monoclonal Antibodies Block SHIV Infection in Macaques. J Exp Med (2014) 211(10):2061-74. doi: 10.1084/jem.20132494

29. Martinez-Navio JM, Fuchs SP, Pedreno-Lopez S, Rakasz EG, Gao G, Desrosiers RC. Host Anti-Antibody Responses Following Adeno-Associated Virus-Mediated Delivery of Antibodies Against HIV and SIV in Rhesus Monkeys. Mol Ther (2016) 24(1):76-86. doi: 10.1038/mt.2015.191

30. Easterhoff D, Pollara J, Luo K, Janus B, Gohain N, Williams LD, et al. HIV Vaccine Delayed Boosting Increases Env Variable Region 2-Specific Antibody Effector Functions. JCI Insight (2020) 5(2):e131437. doi: 10.1172/ jci.insight. 131437

31. Easterhoff D, Pollara J, Luo K, Tolbert WD, Young B, Mielke D, et al. Boosting With AIDSVAX B/E Enhances Env Constant Region 1 and 2 AntibodyDependent Cellular Cytotoxicity Breadth and Potency. J Virol (2020) 94(4): e01120-19. doi: 10.1128/JVI.01120-19

32. Santra S, Tomaras GD, Warrier R, Nicely NI, Liao HX, Pollara J, et al. Human Non-Neutralizing HIV-1 Envelope Monoclonal Antibodies Limit the Number of Founder Viruses During SHIV Mucosal Infection in Rhesus Macaques. PloS Pathog (2015) 11(8):e1005042. doi: 10.1371/journal.ppat.1005042

33. Saunders KO, Pegu A, Georgiev IS, Zeng M, Joyce MG, Yang ZY, et al. Sustained Delivery of a Broadly Neutralizing Antibody in Nonhuman Primates Confers Long-Term Protection Against Simian/Human Immunodeficiency Virus Infection. J Virol (2015) 89(11):5895-903. doi: 10.1128/JVI.00210-15

34. Ramesh A, Darko S, Hua A, Overman G, Ransier A, Francica JR, et al. Structure and Diversity of the Rhesus Macaque Immunoglobulin Loci Through Multiple De Novo Genome Assemblies. Front Immunol (2017) 8:1407. doi: $10.3389 /$ fimmu.2017.01407

35. Fouts TR, Tuskan R, Godfrey K, Reitz M, Hone D, Lewis GK, et al. Expression and Characterization of a Single-Chain Polypeptide Analogue of the Human Immunodeficiency Virus Type 1 Gp120-CD4 Receptor Complex. J Virol (2000) 74(24):11427-36. doi: 10.1128/JVI.74.24.11427-11436.2000

36. Otwinowski Z, Minor W, Charles W. "Processing of X-Ray Diffraction Data Collected in Oscillation Mode,". In: Meth Enzymol. Academic Press (1997). p. 307-26.

37. Collaborative Computational Project N. The CCP4 Suite: Programs for Protein Crystallography. Acta Crystallogr D Biol Crystallogr (1994) $50(\mathrm{Pt}$ 5):760-3. doi: 10.1107/S0907444994003112

38. Adams PD, Afonine PV, Bunkoczi G, Chen VB, Davis IW, Echols N, et al. PHENIX: A Comprehensive Python-Based System for Macromolecular Structure Solution. Acta Crystallogr D Biol Crystallogr (2010) D66:213-21. doi: $10.1107 / S 0907444909052925$

39. Weiss MS. GlobalIndicators of X-Ray Data Quality. J Appl Cryst 34 (2001):130-5. doi: 10.1107/S0021889800018227

40. Karplus PA, Diederichs K. Linking Crystallographic Model and Data Quality. Science (2012) 336:1030-3. doi: 10.1126/science.1218231

41. Popov AN, Bourenkov GP. Choice of Data-Collection Parameters Based on Statistic Modelling. Acta Crystallogr D Biol Crystallogr (2003) 59:1145-53. doi: 10.1107/S0907444903008163

42. Brunger AT. Free R Value: Cross-Validation in Crystallography. In: Methods in Enzymology. Academic Press (1997). p. 366-96.

43. Mielke D, Bandawe G, Pollara J, Abrahams MR, Nyanhete T, Moore PL, et al. Antibody-Dependent Cellular Cytotoxicity (ADCC)-Mediating Antibodies Constrain Neutralizing Antibody Escape Pathway. Front Immunol (2019) 10:2875. doi: 10.3389/fimmu.2019.02875

44. Hoxie JA, LaBranche CC, Endres MJ, Turner JD, Berson JF, Doms RW, et al. CD4-Independent Utilization of the CXCR4 Chemokine Receptor by HIV-1 and HIV-2. J Reprod Immunol (1998) 41(1-2):197-211. doi: 10.1016/s01650378(98)00059-x 
45. Schouest B, Leslie GJ, Hoxie JA, Maness NJ. Tetherin Downmodulation by SIVmac Nef Lost With the H196Q Escape Variant is Restored by an Upstream Variant. PloS One (2020) 15(8):e0225420. doi: 10.1371/journal.pone.0225420

46. Pollara J, Tay MZ, Edwards RW, Goodman D, Crowley AR, Edwards RJ, et al. Functional Homology for Antibody-Dependent Phagocytosis Across Humans and Rhesus Macaques. Front Immunol (2021) 12:678511. doi: 10.3389/ fimmu.2021.678511

47. Li H, Wang S, Kong R, Ding W, Lee FH, Parker Z, et al. Envelope Residue 375 Substitutions in Simian-Human Immunodeficiency Viruses Enhance CD4 Binding and Replication in Rhesus Macaques. Proc Natl Acad Sci USA (2016) 113(24):E3413-22. doi: 10.1073/pnas.1606636113

48. Song RJ, Chenine AL, Rasmussen RA, Ruprecht CR, Mirshahidi S, Grisson RD, et al. Molecularly Cloned SHIV-1157ipd3n4: A Highly ReplicationCompetent, Mucosally Transmissible R5 Simian-Human Immunodeficiency Virus Encoding HIV Clade C Env. J Virol (2006) 80(17):8729-38. doi: 10.1128/JVI.00558-06

49. Pollara J, Bonsignori M, Moody MA, Liu P, Alam SM, Hwang KK, et al. HIV-1 Vaccine-Induced C1 and V2 Env-Specific Antibodies Synergize for Increased Antiviral Activities. J Virol (2014) 88(14):7715-26. doi: 10.1128/JVI.00156-14

50. Johnson S, Oliver C, Prince GA, Hemming VG, Pfarr DS, Wang SC, et al. Development of a Humanized Monoclonal Antibody (MEDI-493) With Potent In Vitro and In Vivo Activity Against Respiratory Syncytial Virus. J Infect Dis (1997) 176(5):1215-24. doi: 10.1086/514115

51. Pollara J, Hart L, Brewer F, Pickeral J, Packard BZ, Hoxie JA, et al. HighThroughput Quantitative Analysis of HIV-1 and SIV-Specific ADCCMediating Antibody Responses. Cytometry A (2011) 79(8):603-12. doi: $10.1002 /$ cyto.a. 21084

52. Ackerman ME, Moldt B, Wyatt RT, Dugast AS, McAndrew E, Tsoukas S, et al. A Robust, High-Throughput Assay to Determine the Phagocytic Activity of Clinical Antibody Samples. J Immunol Methods (2011) 366(1-2):8-19. doi: 10.1016/j.jim.2010.12.016

53. Tay MZ, Liu P, Williams LD, McRaven MD, Sawant S, Gurley TC, et al. Antibody-Mediated Internalization of Infectious HIV-1 Virions Differs Among Antibody Isotypes and Subclasses. PloS Pathog (2016) 12(8): e1005817. doi: 10.1371/journal.ppat.1005817

54. Bonsignori M, Zhou T, Sheng Z, Chen L, Gao F, Joyce MG, et al. Maturation Pathway From Germline to Broad HIV-1 Neutralizer of a CD4-Mimic Antibody. Cell (2016) 165(2):449-63. doi: 10.1016/j.cell.2016.02.022

55. Bonsignori M, Montefiori DC, Wu X, Chen X, Hwang KK, Tsao CY, et al. Two Distinct Broadly Neutralizing Antibody Specificities of Different Clonal Lineages in a Single HIV-1-Infected Donor: Implications for Vaccine Design. J Virol (2012) 86(8):4688-92. doi: 10.1128/JVI.07163-11

56. Whittle JR, Zhang R, Khurana S, King LR, Manischewitz J, Golding H, et al. Broadly Neutralizing Human Antibody That Recognizes the ReceptorBinding Pocket of Influenza Virus Hemagglutinin. Proc Natl Acad Sci USA (2011) 108(34):14216-21. doi: 10.1073/pnas.1111497108

57. Worley MJ, Fei K, Lopez-Denman AJ, Kelleher AD, Kent SJ, Chung AW. Neutrophils Mediate HIV-Specific Antibody-Dependent Phagocytosis and ADCC. J Immunol Methods (2018) 457:41-52. doi: 10.1016/j.jim.2018.03.007

58. Liu P, Yates NL, Shen X, Bonsignori M, Moody MA, Liao HX, et al. Infectious Virion Capture by HIV-1 Gp120-Specific IgG From RV144 Vaccinees. J Virol (2013) 87(14):7828-36. doi: 10.1128/JVI.02737-12

59. Liu P, Williams LD, Shen X, Bonsignori M, Vandergrift NA, Overman RG, et al. Capacity for Infectious HIV-1 Virion Capture Differs by Envelope Antibody Specificity. J Virol (2014) 88(9):5165-70. doi: 10.1128/JVI.03765-13

60. Mayer KH, Seaton KE, Huang Y, Grunenberg N, Isaacs A, Allen M, et al. Safety, Pharmacokinetics, and Immunological Activities of Multiple Intravenous or Subcutaneous Doses of an Anti-HIV Monoclonal Antibody, VRC01, Administered to HIV-Uninfected Adults: Results of a Phase 1 Randomized Trial. PloS Med (2017) 14(11):e1002435. doi: 10.1371/journal.pmed.1002435

61. Buchacher A, Predl R, Strutzenberger K, Steinfellner W, Trkola A, Purtscher $\mathrm{M}$, et al. Generation of Human Monoclonal Antibodies Against HIV-1 Proteins; Electrofusion and Epstein-Barr Virus Transformation for Peripheral Blood Lymphocyte Immortalization. AIDS Res Hum Retroviruses (1994) 10(4):359-69. doi: 10.1089/aid.1994.10.359

62. Gohain N, Tolbert WD, Acharya P, Yu L, Liu T, Zhao P, et al. Co-Crystal Structures of Antibody N60-I3 and Antibody JR4 in Complex With Gp120 Define More
Cluster A Epitopes Involved in Effective Antibody-Dependent Effector Function Against HIV-1. J Virol (2015) 89(17):8840-54. doi: 10.1128/JVI.01232-15

63. Luo K, Liao HX, Zhang R, Easterhoff D, Wiehe K, Gurley TC, et al. Tissue Memory B Cell Repertoire Analysis After ALVAC/AIDSVAX B/E Gp120 Immunization of Rhesus Macaques. JCI Insight (2016) 1(20):e88522. doi: $10.1172 /$ jci.insight. 88522

64. Rerks-Ngarm S, Pitisuttithum P, Excler JL, Nitayaphan S, Kaewkungwal J, Premsri N, et al. Randomized, Double-Blind Evaluation of Late Boost Strategies for HIV-Uninfected Vaccine Recipients in the RV144 HIV Vaccine Efficacy Trial. J Infect Dis (2017) 215(8):1255-63. doi: 10.1093/ infdis/jix099

65. Tolbert WD, Van V, Sherburn R, Tuyishime M, Yan F, Nguyen DN, et al. Recognition Patterns of the $\mathrm{C} 1 / \mathrm{C} 2$ Epitopes Involved in Fc-Mediated Response in HIV-1 Natural Infection and the RV114 Vaccine Trial. mBio (2020) 11(3):e00208-20. doi: 10.1128/mBio.00208-20

66. Zolla-Pazner S, Alvarez R, Kong XP, Weiss S. Vaccine-Induced V1V2-Specific Antibodies Control and or Protect Against Infection With HIV, SIV and SHIV. Curr Opin HIV AIDS (2019) 14(4):309-17. doi: 10.1097/ COH.0000000000000551

67. Arthos J, Cicala C, Martinelli E, Macleod K, Van Ryk D, Wei D, et al. HIV-1 Envelope Protein Binds to and Signals Through Integrin Alpha4beta7, the Gut Mucosal Homing Receptor for Peripheral T Cells. Nat Immunol (2008) 9 (3):301-9. doi: 10.1038/ni1566

68. Tassaneetrithep B, Tivon D, Swetnam J, Karasavvas N, Michael NL, Kim JH, et al. Cryptic Determinant of Alpha4beta7 Binding in the V2 Loop of HIV-1 Gp120. PloS One (2014) 9(9):e108446. doi: 10.1371/journal.pone.0108446

69. Peachman KK, Karasavvas N, Chenine AL, McLinden R, Rerks-Ngarm S, Jaranit K, et al. Identification of New Regions in HIV-1 Gp120 Variable 2 and 3 Loops That Bind to Alpha4beta7 Integrin Receptor. PloS One (2015) 10(12): e0143895. doi: 10.1371/journal.pone.0143895

70. Wiehe K, Easterhoff D, Luo K, Nicely NI, Bradley T, Jaeger FH, et al. Antibody Light-Chain-Restricted Recognition of the Site of Immune Pressure in the RV144 HIV-1 Vaccine Trial is Phylogenetically Conserved. Immunity (2014) 41(6):909-18. doi: 10.1016/j.immuni.2014.11.014

71. Almagro JC, Daniels-Wells TR, Perez-Tapia SM, Penichet ML. Progress and Challenges in the Design and Clinical Development of Antibodies for Cancer Therapy. Front Immunol (2017) 8:1751. doi: 10.3389/fimmu.2017.01751

72. Lu RM, Hwang YC, Liu IJ, Lee CC, Tsai HZ, Li HJ, et al. Development of Therapeutic Antibodies for the Treatment of Diseases. J BioMed Sci (2020) 27:1. doi: 10.1186/s12929-019-0592-z

73. Fuchs SP, Martinez-Navio JM, Piatak M Jr, Lifson JD, Gao G, Desrosiers RC. AAV-Delivered Antibody Mediates Significant Protective Effects Against SIVmac239 Challenge in the Absence of Neutralizing Activity. PloS Pathog (2015) 11(8):e1005090. doi: 10.1371/journal.ppat.1005090

74. Priddy FH, Lewis DJM, Gelderblom HC, Hassanin H, Streatfield C, LaBranche C, et al. Adeno-Associated Virus Vectored Immunoprophylaxis to Prevent HIV in Healthy Adults: A Phase 1 Randomised Controlled Trial. Lancet HIV (2019) 6(4):e230-9. doi: 10.1016/S2352-3018(19)30003-7

75. Casazza JP, Cale EM, Narpala S, Novik L, Yamshchikov GV, Lin BC, et al. "Durable HIV-1 Antibody Production in Humans After AAV8-Mediated Gene Transfer". In: Conference on Retroviruses and Opportunistic Infections (2021). (virtual).

76. Harding FA, Stickler MM, Razo J, DuBridge R. The Immunogenicity of Humanized and Fully Human Antibodies: Residual Immunogenicity Resides in the CDR Regions. MAbs (2010) 2(3):256-65. doi: 10.4161/mabs.2.3.11641

Author Disclaimer: The views expressed in this presentation are those of the authors and do not reflect the official policy or position of the Uniformed Services University, US Army, the Department of Defense, or the US Government.

Conflict of Interest: The authors declare that the research was conducted in the absence of any commercial or financial relationships that could be construed as a potential conflict of interest.

Publisher's Note: All claims expressed in this article are solely those of the authors and do not necessarily represent those of their affiliated organizations, or those of the publisher, the editors and the reviewers. Any product that may be evaluated in 
this article, or claim that may be made by its manufacturer, is not guaranteed or endorsed by the publisher.

Copyright (๑ 2022 Tolbert, Nguyen, Tuyishime, Crowley, Chen, Jha, Goodman, Bekker, Mudrak, DeVico, Lewis, Theis, Pinter, Moody, Easterhoff, Wiehe, Pollara, Saunders, Tomaras, Ackerman, Ferrari and Pazgier. This is an open-access article distributed under the terms of the Creative Commons Attribution License (CC BY). The use, distribution or reproduction in other forums is permitted, provided the original author(s) and the copyright owner(s) are credited and that the original publication in this journal is cited, in accordance with accepted academic practice. No use, distribution or reproduction is permitted which does not comply with these terms. 